\title{
Endothelial Dysfunction in SARS CoV-2 Infection
}

\author{
Francesco Nappi ${ }^{1, *}$ and Sanjeet Singh Avtaar Singh ${ }^{2}$ \\ 1 Department of Cardiac Surgery, Centre Cardiologique du Nord. 93200, Saint-Denis, Paris, France \\ 2 Department of Cardiothoracic Surgery, Aberdeen Royal Infirmary, Aberdeen, AB25 2ZN, United Kingdom \\ * Correspondence: francesconappi2@gmail.com
}

\begin{abstract}
One of the hallmarks of the SARS-CoV-2 infection has been the inflammatory process that played a role in its pathogenesis, resulting in mortality within susceptible individuals. This uncontrolled inflammatory process leads to severe systemic symptoms via multiple pathways, however, the role of endothelial dysfunction and thrombosis have not been truly explored. This review aims to highlight the pathogenic mechanisms of these inflammatory triggers leading to thrombogenic complications. There are direct and indirect pathogenic pathways of the infection that are examined in detail. We also describe the case of carotid artery thrombosis in a patient following the SARSCoV-2 infection, while reviewing the literature on the role of ACE2, the endothelium, and the different mechanisms by which SARS-CoV-2 may manifest both acutely and chronically. We also highlight differences from the other coronaviruses that have made this infection pandemic with similarities to the influenza virus.
\end{abstract}

Keywords: : Endothelial Dysfunction; SARS-CoV-2 infection; Thrombosis, Angiotensin-converting enzyme-2; Angiogenesis.

\section{Introduction}

The clinical therapeutics that have been suggested in the course of SARS CoV-2 infection have immediately noted the uncontrolled inflammatory process as an important hurdle to overcome. Endothelial dysfunction and thrombosis are consequences of the cataclysmic inflammatory trigger. Here we describe the case of a carotid artery thrombosis that occurred in a patient with Covid 19 to highlight endothelial dysfunction during SARS CoV-2 infection. We believe that the data presented in this overview could provide a basis for understanding the role of endothelial dysfunction and assist virologists and health providers (family doctors, internists, cardiologists, and intensivists) in the physician-patient discussion about the risks and expectations after the involvement of endothelium in SARS-Cov-2 infection.

A 47-year-old woman with no comorbidities tested positive for SARS-CoV-2 via an RNA test presented with right upper paresis and headache 15 days after the onset of mild respiratory symptoms. The patient was treated with domiciliary oxygen and managed conservatively prior to the event. Computed tomography (CT) and magnetic resonance imaging (MRI) revealed an ischemic stroke at the junction of the perfusion territories of the left anterior cerebral artery (ACA) and the left middle cerebral artery (MCA). Carotidspecific imaging showed a thrombus of the bulb of the left common carotid artery (LCA) extending into the left internal carotid artery and responsible for a $75 \%$ vessel stenosis without of any underlying atheroma (Figure 1). 

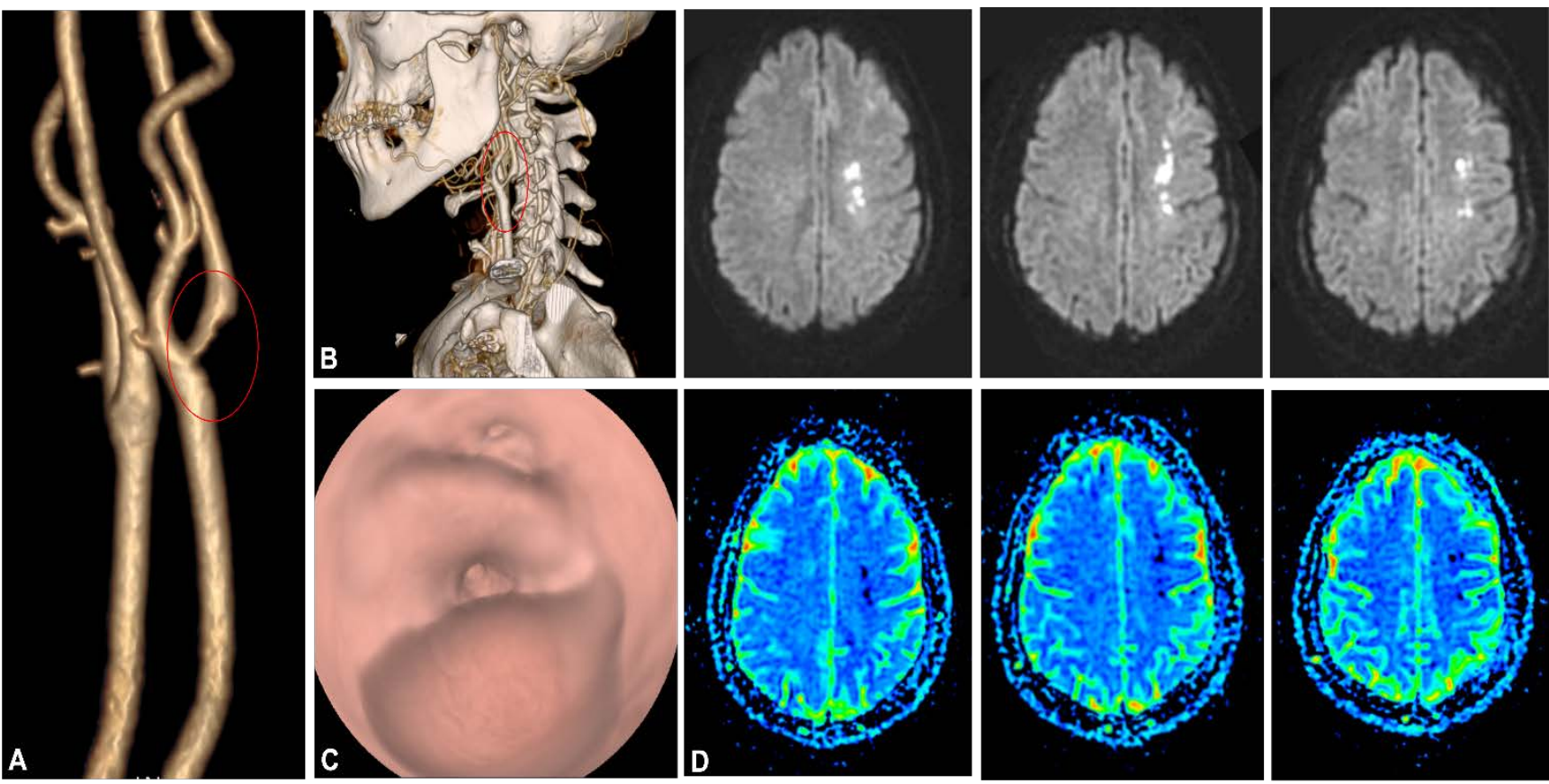

Figure 1. A-B: CT angiogram with three-dimensional reconstruction depicting thrombotic stenosis of the left carotid artery bifurcation extending into the internal carotid artery (red circles). C: CT Virtual Intravascular Endoscopy of the left carotid bifurcation demonstrating a large thrombus causing significant stenosis of the left carotid artery. D: MRI brain diffusionweighted imaging showing punctiform lesions in hypersignal diffusion visible in left fronto-parietal FLAIR at the level of the left ACA-MCA territory, with decreased apparent diffusion coefficient. No hemorrhagic changes. Gyriform enhancement in relation to the lesions indicating a rupture of the blood-brain barrier. Preserved patency of circle of Willis. Abbreviation: ACA, Anterior cerebral artery; CT,computed tomography; MCA, Middle cerebral artery; MRI, magnetic resonance.

Blood tests results showed mild leucopenia, but no elevation of inflammatory markers including a C-reactive protein (CRP) of $<3 \mathrm{mg} / \mathrm{L}$ and procalcitonin of $0.02 \mathrm{pg} / \mathrm{l}$. No abnormalities of the coagulation profile were noted and antiphospholipid antibodies, anticardiolipin, and autoimmunity screening were negative. ECG showed sinus rhythm and echocardiography ruled out causes of cryptogenic stroke. Anticoagulation by low-molecular-weight-heparin and statin treatment was commenced with clinical improvement and total resolution of the thrombotic occlusion at a 10-day follow-up CT-scan (Figure 2).

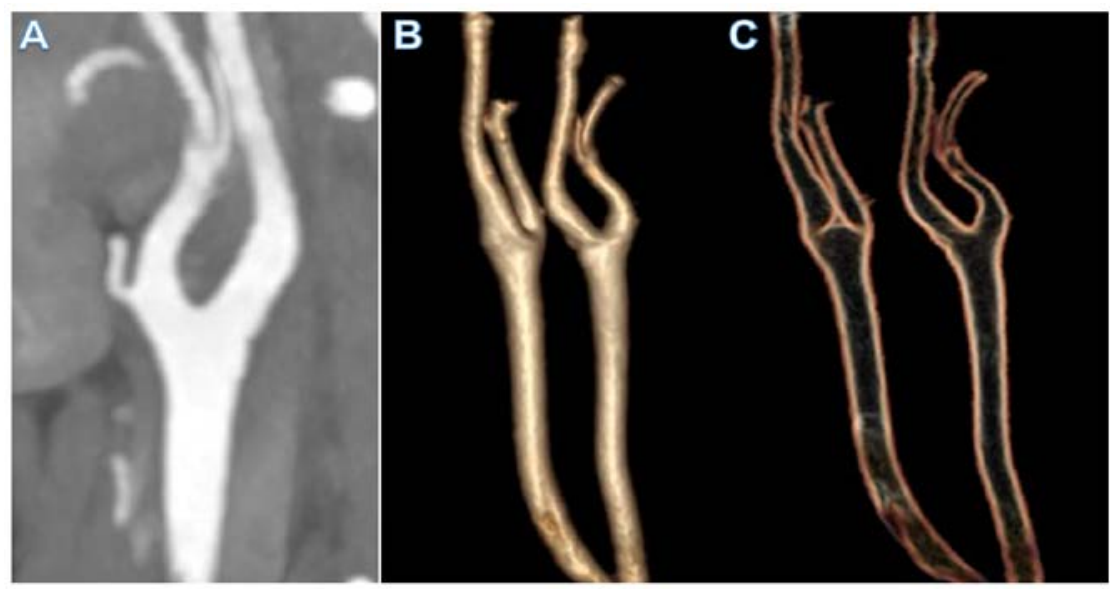

Figure 2. A-C: CT angiogram of the supra-aortic arteries 10 days after institution of low-molecular-weight-heparin Table 3. D volume rendering). 


\section{The Clinical Problem}

Coronaviruses (CoVs) comprise a large family of single-stranded, positive-sense RNA viruses. They have a capacity for rapid mutation and recombination. Coronaviruses can induce respiratory or intestinal infections in humans and animals ${ }^{1-3}$

People who develop acute respiratory infections, including influenza, respiratory syncytial virus, and bacterial pneumonia, may experience progression of the disease to cardiovascular disease (CVD). ${ }^{4-8}$ With the emergence of the severe acute respiratory syndrome virus coronavirus 2 (SARS-CoV-2), which causes coronavirus disease 2019 (COVID-19), the pandemic has rapidly highlighted these major cardiovascular pathologies. The development of CVD as a progression of COVID 19 is generally associated with comorbidities, which can increase the incidence and severity of infectious diseases. ${ }^{7-11}$ This rapid progression of the infection has brought out two conditions. In the first, it was highlighted that a large percentage of patients who contract COVID 19 have underlying CVD. ${ }^{12,13}$ The second condition revealed that frequently the vascular complications due to COVID 19 are not sometimes related to a pre-existing vascular pathology. ${ }^{13-15}$

The most relevant finding to emerge from COVID 19 severe acute respiratory syndrome is the devastating global public health crisis. The morbidity and mortality associated with COVID-19 are usually attributed to severe acute respiratory distress syndrome (ARDS) resulting in severe lung function impairment and cardiovascular complications including myocardial infarction (MI). Additionally, disability and death in COVID 19 patients can be caused by ischemic stroke and pulmonary embolism (PE). ${ }^{14-19}$

Understanding the effects of COVID-19 on the pulmonary and the cardiovascular system is not only fundamental but allows the provision of complete and satisfactory medical assistance to patients with cardiac-related comorbidities. At the same time, the manifestation of neurological clinical signs, due to endothelial dysfunction with or without systemic atherosclerotic lesions, can occur in patients with COVID-19.20-22 Prompt diagnosis in these patients can limit the number of neglected cases of infection, delayed diagnosis and avoid misdiagnosis. In addition, rapid diagnosis allows timely medical treatment and prevent further transmission of the SARS-CoV-2 infection. ${ }^{20-22}$

Since the beginning of the SARS-CoV-2 pandemic, patients with COVID-19 have been characterized by a higher frequency of arterial and venous thrombosis, which has been linked to systemic inflammation, prolonged bed rest, and a prothrombotic environment. ${ }^{23,24}$ There is now abundant evidence that arterial and venous thromboembolism (VTE) is a major cardiovascular risk in patients with COVID-19 potentially leading to neurological complications. ${ }^{25-28}$ The percentage of patients experiencing VTE is higher in intensive care unit (ICU) admissions with symptomatic disease reaching $25 \%$, but the rate stands at $69 \%$ when routine venous ultrasound scans are performed. ${ }^{27,28}$ Several studies have reported a high prevalence of microthrombosis in situ, which may be related to endothelial damage directly caused by viral infection. ${ }^{14-16,28,29}$

Concerns related to quantifying the risk of cardiovascular and neurological complications depend on the heterogeneity of the patient population with COVID-19 and direct SARS-CoV-2 infection of the endothelium remain unclear ${ }^{30}$ with both prohibiting accurate determination of risk. In addition, the different methods of thromboprophylaxis, the definitions of variable outcomes, and the restriction of assessments in the ICU setting should be considered. Although antithrombotic therapy is recommended for patients hospitalized with COVID-19, with the aim of preventing thromboembolic cardiovascular events, arterial and venous thromboembolism still occurred in a subgroup of patients who have received standard thromboprophylaxis at the appropriate time. ${ }^{31-33}$ Graphical Abstract 


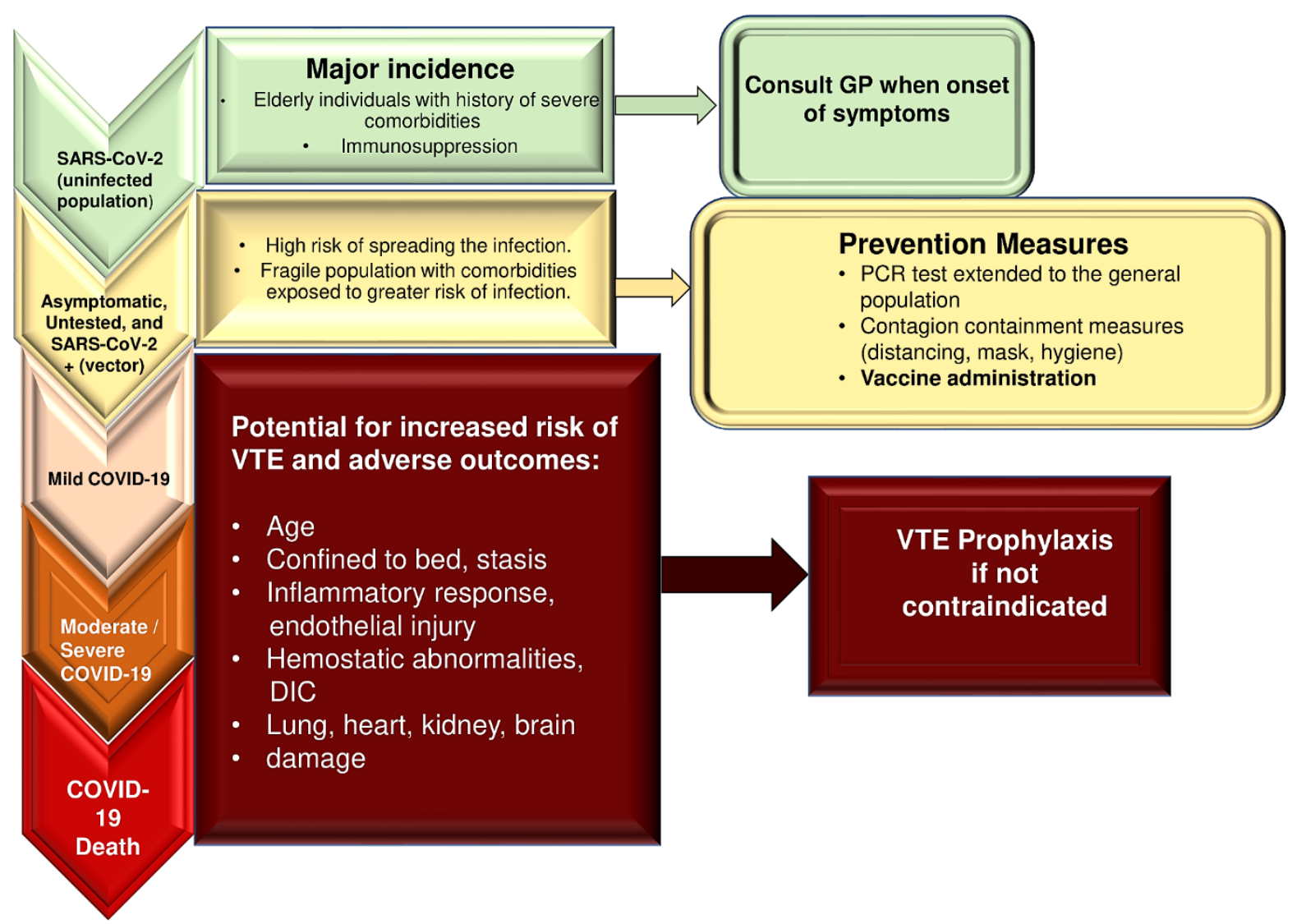

Graphical abstract. The infection from SARS Cov2caused a variability in the manifestation of the disease. This explains the different population rates of infection and the distinct mortality rates of manifest cases in various regions and countries. Inflammatory response, increased age, and bed rest, which are most frequently seen in severe coronavirus disease 2019 (COVID-19), may contribute to thrombosis and adverse events resulting from multiorgan involvement.

Abbreviations: COVID-19, coronavirus disease 2019; DIC, disseminated intravascular coagulation; SARS-CoV-2 , severe acute respiratory syndrome-coronavirus-2; VTE, venous thromboembolism.

\section{Pathophysiology}

\subsection{Coronavirus infection in humans}

The name "coronavirus" derives from the presence of the crown-shaped spikes on their surface. Coronaviruses belong to the Coronavirinae subfamily which is further classified into 4 phylogenetic groups: the $\operatorname{CoV} \alpha, \beta, \gamma$ and $\delta$. The $\alpha$ and $\beta$ groupings are pathologically harmful because they can cause infection in humans. $7,34,35$ Coronaviruses consist of 4 main structural proteins: the peak (S) protein which mediates the binding of the viral particle to the host receptor and subsequent fusion of the virus and cell membrane. The nucleocapsid $(\mathrm{N})$ protein, the membrane protein $(\mathrm{M})$ and the envelope $(\mathrm{E})$ proteins also belong to the structure of the coronavirus. ${ }^{6,36}$

In the mid-1960s, investigators identified the first human $\mathrm{CoV}(\mathrm{HCoV})$ from embryonic tracheal organ cultures and until 2003, only $2 \mathrm{HCoV}$ species were acknowledged as pathogens: $\mathrm{HCoV}-229 \mathrm{E}$ and $\mathrm{HCoV}-\mathrm{OC} .{ }^{37} \mathrm{In} 2003$ two other types of $\mathrm{HCoV}$ emerged leading to severe acute respiratory syndrome coronavirus (SARS-CoV) 40 and Middle East Respiratory Syndrome coronavirus (MERS-CoV). ${ }^{38}$ In 2019 a newly identified SARS-CoV2 caused one of the more lethal respiratory infections in humans., ${ }^{911,39-44}$ Thus, there are currently 7 known human coronaviruses that have the potential of infecting humans but 
three of these strains are highly pathogenic [SARS-CoV, SARS-CoV-2, and Middle East respiratory syndrome (MERS). The less virulent $\mathrm{CoV}$ strains include $\mathrm{HCoV}-229 \mathrm{E}, \mathrm{HCoV}$ NL63, HCoV-OC43, and HCoV-HKU1 are often self-terminating infections and usually termed as"common colds". ${ }^{42,45}$

\subsection{SARS Cov-2 host interaction}

We learned that cells are the gateway to viral infection through a binding interaction between viruses and the host's cell surface and this interplay is mediated by a certain affinity with surface receptors. Viral trophism towards a given cell line is regulated by the expression and distribution of structured receptors on the cell surface that mediate virus entry. Therefore, receptors represent the crucial feature that specifically defines tissue infection as well as the pathogenesis of the disease.

Virologists discovered that SARS-CoV-2 is the third human coronavirus that uses the enzyme angiotensin-converting peptidase 2 (ACE2) as the gate of entry for cells ${ }^{46}$. Understanding the mechanism that regulates the interaction between SARS-CoV-2 and ACE2 is a fundamental step in determining both the trophism of the virus for tissues and the progression of SARS-CoV-2 infection, as well as its evolution towards more severe forms of COVID-19. As a result, the knowledge of the cellular processes that form the cornerstone of SARS-CoV-2 infection could represent the turning point in the identification of treatments that prevent the progression of the infection towards the development of complicated disease, thus favoring a reduction of mortality.

ACE2 is configured as a transmembrane protein that plays the main role in homeostasis of the cardiovascular system in counterbalancing the effects of the angiotensin-converting enzyme (ACE) ${ }^{47} \mathrm{ACE}$ acts as a catalyst in the conversion of angiotensin I to angiotensin II. This octapeptide is very active in exerting a vasopressor action, mediating vascular contraction with an increase of blood pressure, and in promoting a proinflammatory activity. ACE2 is a carboxypeptidase active in the conversion of angiotensin II into the heptapeptide angiotensin- (1-7) to facilitate its function as an antagonist of angiotensin II. This work is mainly expressed by exercising anti-inflammatory and vasodilatory activity. Substantial evidence suggests elevated expression of ACE is in vascular endothelial cells of the lungs, and it is therefore likely that the level of angiotensin II is also increased in lung vascular cells. In support of this finding, there is evidence that in mouse models where acute lung injury was induced, ACE2 deletion causes more severe disease, thus suggesting a protective action of ACE2 in lung tissue due to its role in reducing the levels of the pro-inflammatory angiotensin II. ${ }^{47}$

Since ACE2 is the SARS-CoV-2 receptor and as reported in many cases of virus-host interaction, viral receptor expression is down-regulated in infected cells. This genetic regulation with reduced expression of the ACE2 receptor was noted in the lungs of mice with SARS-CoV infection. Lung damage caused by SARS-CoV and SARS-CoV-2 can be caused by the depletion of ACE II, which therefore plays a central role in maintaining the infection, as also evidenced by the high angiotensin II levels that were reported in the plasma of patients with COVID-19. However, patients with MERS-CoV infection experienced lung disease similar to that induced by SARS-Cov-2 without the direct involvement of ACE2. Therefore, other factors are implicated in the genesis of coronavirus-mediated infection. Figure 3 


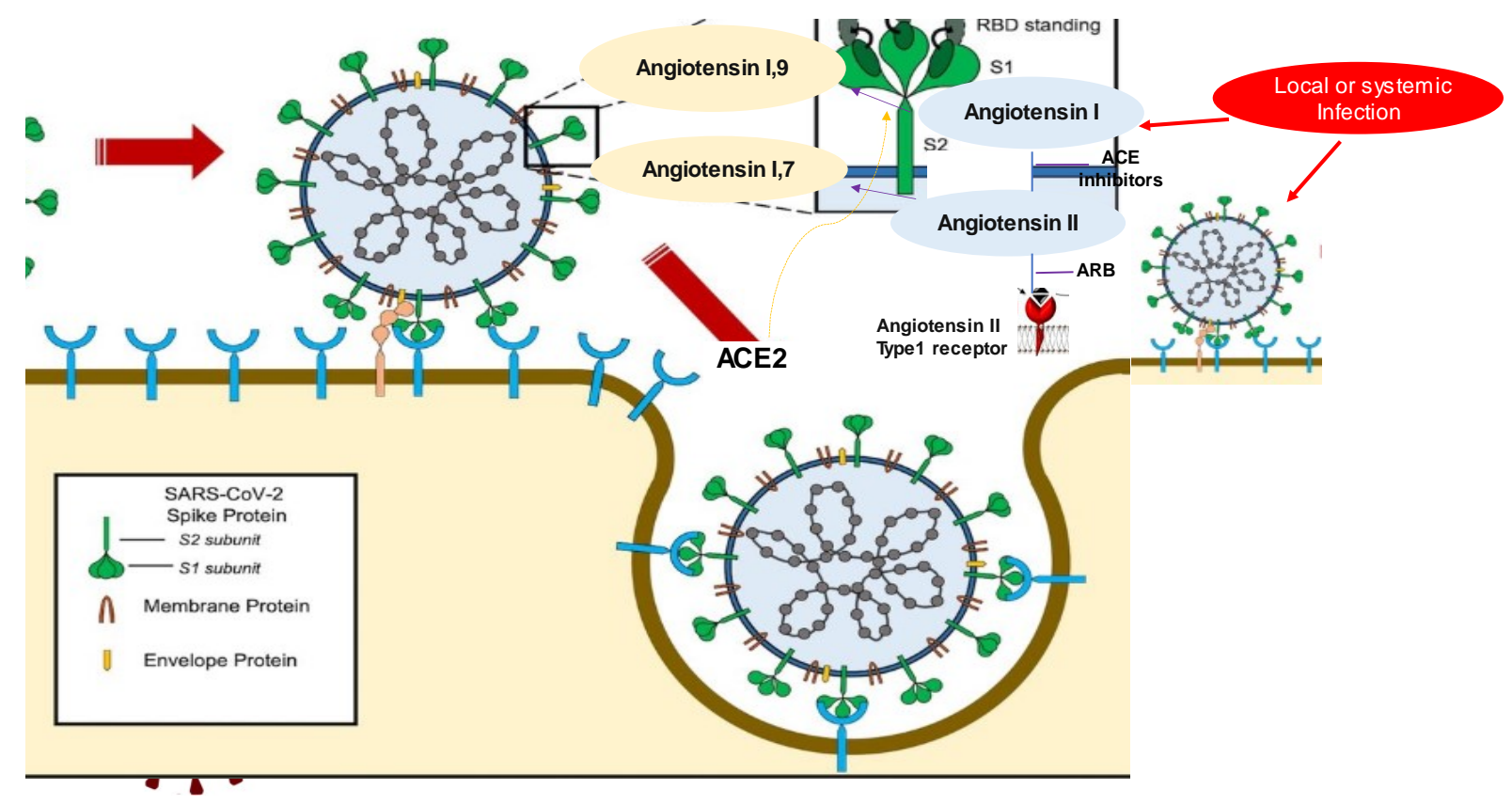

Figure 3. SARS-Cov-2 uses the enzyme angiotensin converting peptidase 2 (ACE2) as the gate of entry for cells. The trophism of the virus for tissues lead to the inflammatory profile pattern before and after SARS-CoV-2 infection. The initial entry of severe acute respiratory syndrome coronavirus 2 (SARS-CoV-2) into cells is shown with involvement mainly of type II pneumocytes. S glycoproteins of SARS CoV-2 (SARS-2-S) binds to its functional receptor, the angiotensin-converting enzyme 2 (ACE2). Host cell surface proteases such as TMPRSS2 cleave the full-length spike protein (S0) converting it to its S2 site through a complex mechanism mediated by the selective function of the host's furin. After endocytosis of the viral complex, surface ACE2 is further down-regulated, resulting in without obstacles storage of angiotensin II. Local activation of the renin-angiotensin-aldosterone system may mediate lung injury responses to viral injuries.

Abbreviations: ACE2 , angiotensin-converting enzyme 2; ARB, angiotensin-receptor blocker; CVD, cardiovascular disease; RBD, receptor binding domain; SARS-CoV-2, severe acute respiratory syndrome coronavirus 2; TMPRSS2, transmembrane serine protease 2 .

\subsection{Functional characteristics of Glycoprotein $S$}

As with all coronaviruses, SARS-CoV-2 also has a $180 \mathrm{kDa}(\mathrm{S})$ spike as a structured protein, which serves to identify the key to access cells in the ACE2 receptor. Protein $S$ plays two essential roles: it induces binding to ACE2 from the amino-terminal region, and it promotes the fusion of viral and cell membranes through the carboxy-terminal region ${ }^{48}$. The third crucial step for lung cell infection is the proteolytic activation of spikes that occurs at a host-mediated polybasic furin cleavage site. ${ }^{49,50}$ Evidence has shown that this cleavage site characterizes all spike proteins from patients who have clinically manifested SARS-CoV-2 infection. It is important to note that the furin cleavage site is typical of other highly pathogenic viruses such as the influenza A virus, but is not expressed by SARSCoV.

This scientific finding has prompted researchers to consider that its acquisition likely occurs after recombination with coronaviruses in bats. Therefore, in the light of this discovery, it is possible to state that cellular tropism of SARS-CoV-2 is multiplied by the cleavage process sustained by the furinproteases and could represent the turning point in explaining how transmission from bats to humans has been promoted. ${ }^{51}$ However, the tropism of SARS Cov-2 depends on expression of other cellular proteases that act synergistically to ACE2. Indeed, additional proteases are required for cleavage and act in the fusion of SARS CoV-2 with the host cell membrane. 
In particular the transmembrane serine protease 2 (TMPRSS2) and TMPRSS13, a host cell surface protease cleaves the spike shortly after binding to ACE2. ${ }^{49}$ Following the interaction of protein $S$ with the ACE2 receptor, host cell surface proteases such as TMPRSS2 and TMPRSS13 cleave the full-length spike protein (S0), converting it to its S2 site through a complex mechanism mediated by the selective function of the host's furin. Activation of $S$ glycoproteins of SARS CoV-2 (SARS-2-S) by these surface proteases requires processing of the S1/S2 cleavage loop, in which both the furin recognition motif and extended loop length proved critical. ${ }^{52,53}$

Virology taught us that the greater transmissibility of SARS-CoV-2 is related to relevant replication in the upper airways, which is not disclosed for the other highly pathogenic coronaviruses SARS-CoV and MERS-CoV. The S glycoproteins of different coronaviruses revealed an intrinsic temperature preference, corresponding with the temperature of the upper or lower airways. SARS-2-S and HCoV-229E, which is responsible of a common cold, replicate in an optimal way when the temperature of $33^{\circ} \mathrm{C}$ is produced as in upper airways. Instead, the $\mathrm{S}$ proteins of SARS-CoV and MERS-CoV works better at $37^{\circ} \mathrm{C}$, in accordance with favorable virus replication preference for the lower airways. TMPRSS2 and TMPRSS13 proteases amplify the cell tropism of SARS-CoV-2 because they facilitate SARS-2-S driven access into the host cell through its activation. Both proteases were found to be relevant in the context of authentic virus replication albeit with differences. For example, TMPRSS13 is not active in low pathogenic HCoV-229E because it is not effective as Spike's activity amplifier. ${ }^{52}$

The process of cleavage at the S2 'site facilitates the fusion of viral and cell membranes to deliver viral RNA into the cytosol. ${ }^{54,55}$ In some defined conditions that have been reported, cells exhibit low TMPRSS2 expression which allows the possibility of undertaking alternative pathways of virus uptake, including involving the endolysosomal pathway and cathepsins. ${ }^{52}$ Evidence suggests that the D614G mutation increases the stability of SARS-CoV-2, particularly at $37^{\circ} \mathrm{C}$, and improves its utilization of the cathepsin L alternative pathway. The use of a subsidiary route for virus entry may confer greater stability of the S-glycoprotein. In these two years we have learned that the spike's properties can promote the spread of the virus and potentially explain why the spike-G614 variant that replaced the first D614 variant has become globally predominant. Coronavirus spike protein is adjusted to suit airway temperature and protease conditions to improve virus transmission and pathology. 52

The activity of neuropilin 1 (NRP1) has recently emerged as a protein that works in the fusion between the cell and SARS-CoV-2 for its entry. ${ }^{56,58}$ Neuropilin has the role of receptor that binds the RXXR motif carboxyterminal sequence of the spike exposed after furin cleavage. The precise mechanism of NRP1 in promoting the entry of SARS CoV-2 into cells remains to be clearly determined, but its role may be to amplify infection by involving other types of cells such as endothelial cells. ${ }^{53,59}$ Figure 4 

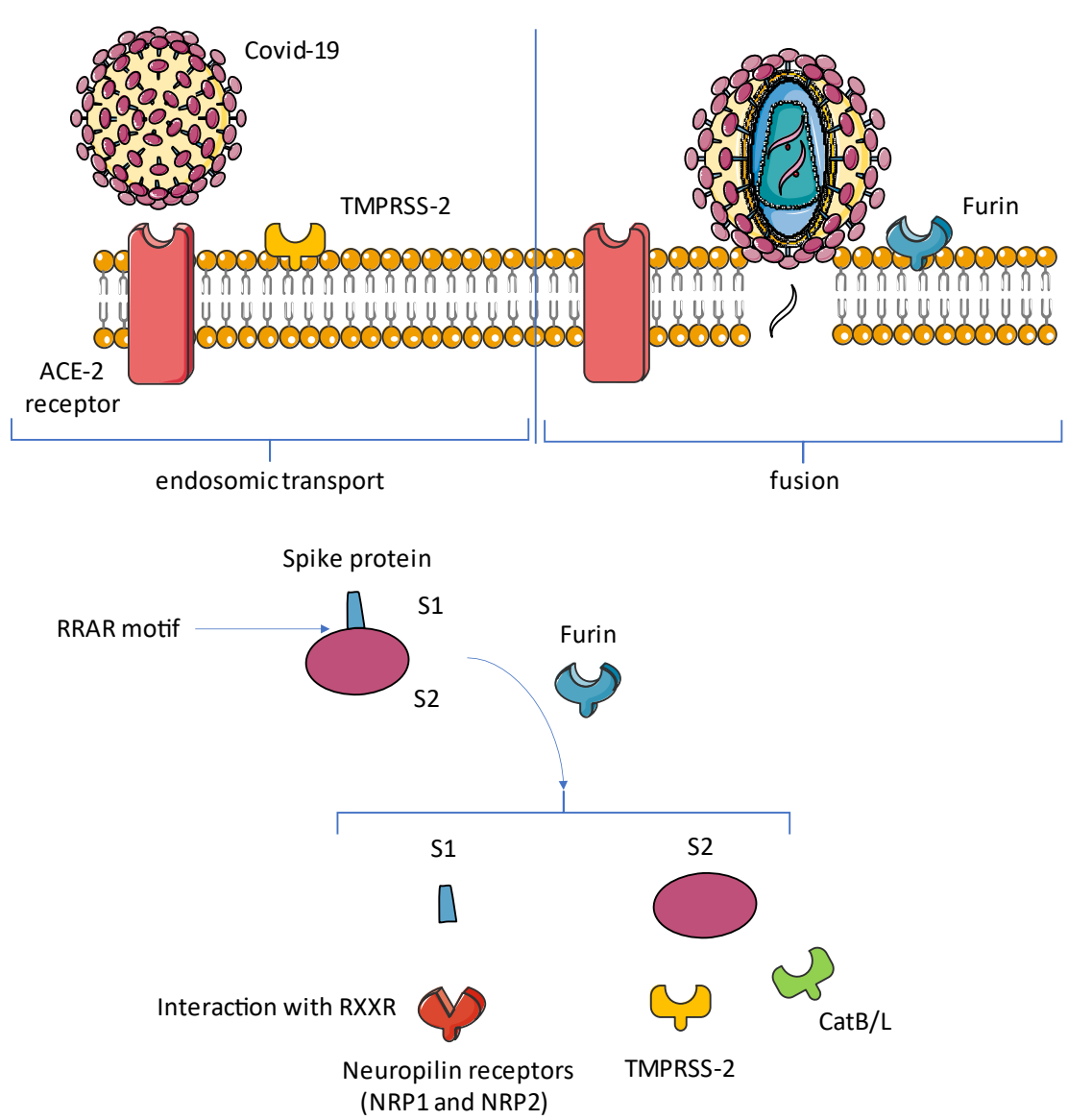

Figure 4. The tropism of SARS Cov-2 depends on expression of proteases that act synergistically to ACE2. Transmembrane serine protease 2 (TMPRSS2) and TMPRSS13 cleave the full-length spike protein (S0), converting it to its S2 site through a complex mechanism mediated by the selective function of the host's furin. Neuropilin 1 (NRP1) binds the RXXR motif carboxyterminal sequence of the spike exposed after furin cleavage. Abbreviations: CatB/L; cathepsin B/L; NRP1, neuropilin; S, spike; others abbreviation in figure 3.

\section{Endothelial Cell Infection and Endotheliitis in SARS-CoV-2 infection}

SARS-CoV-2 infection has very heterogeneous characteristics causing several clinical syndromes of COVID 19 when an involvement of the vascular endothelium is established. The two extreme clinical conditions experienced by patients with COVID 19 are asymptomatic infection or a fatal disease. Evidence from critical ill hospitalizations due to COVID 19 disclosed about $30 \%$ of patients in which a serious disease with progressive lung damage occurred. ${ }^{54,60}$ The unfortunate progression of this pathology is associated with the severe injuries of the vascular compartment resulting in rupture of the vascular barrier and edema $\mathrm{h}$. It should be noted that the patho-anatomical examination of the lesions endotheliitis, thrombosis and marked infiltration of inflammatory cells were associated. ${ }^{61}$

Several studies have suggested that vascular pathology is a major cause of severe disease. As proof of this, investigators have identified thrombotic and microvascular complications as the potent cause of deaths in patients with complicated COVID 19.28,62,63 Arterial and venous thromboembolism, kidney disease and neurological disorders are mandatory among the pathological events responsible for the onset of severe symptoms in COVID 19 patients requiring hospitalization. ${ }^{64,65}$ Figure 5 


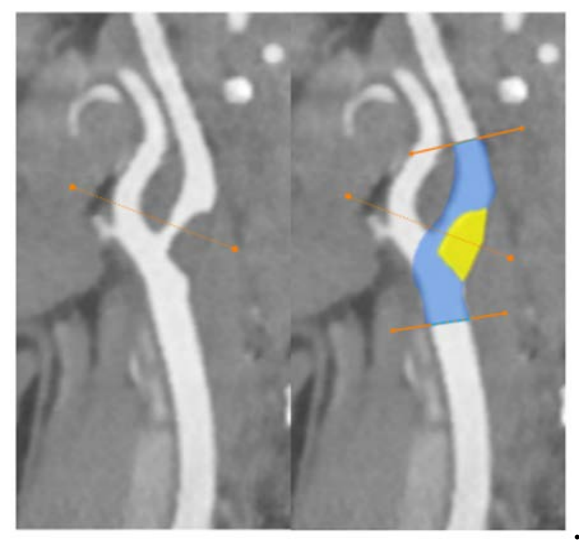

Figure 5. Endothelial cell infection and endotheliitis in criticaly ill hospedalized patient with COVID 19. CT- angiography of the supra-aortic arteries disclosed a significant stenosis of the left carotid artery bifurcation extending into the internal carotid artery.

This suggests a leading role of SARS-CoV-2 in activating the vascular system in a consistent process, potentially responsible for the multi-organ involvement of the infection and the consequential multi-organ failure. However, solid evidence confirming whether viral infection leads to multi-organ failure or the latter is caused by inflammationinduced endothelial activation remains highly controversial and is still an open topic.

As for the cardiovascular system, evidence of its serious involvement leading to complications from SARS-CoV-2 infection was apparent very soon after the respiratory disease. It has been unquestionably highlighted that these complications pose a key threat in COVID-19. The mechanisms that sustain the disproportionate of SARS-CoV-2 infection in patients who experienced with cardiovascular comorbidities, remain unclear. ${ }^{14-16}$

\subsection{Interaction of SARS-CoV-2 and ACE2 receptor: insight of influence on Renin-Angiotensin-}

\section{Aldosterone System Inhibitors}

The tissue and circulating elements that constitute the renin angiotensin system (RAAS) establish an elaborate intersecting network of regulatory and counter-regulatory peptides. As previously reported ACE2 has the key counter-regulatory function mediated by the degradation of angiotensin II to angiotensin- (1-7). ACE2 has the effect of containing the vasoconstriction, sodium retention and fibrosis induced by the production of angiotensin II. Although the primary substrate of ACE2 is angiotensin II, the action of ACE2 is also the catalysis of angiotensin I into angiotensin- (1-9) and it interferes with the hydrolysis of other peptides. ${ }^{66}$ ACE2 has been found expressed in human tissue specimen from 15 organs but it has been widely expressed in the heart and in the kidneys, as well as on the pulmonary alveolar epithelial cells which are the target cells of SARS-CoV-2 infection. ${ }^{67}$ It is important to note that the circulating levels of soluble ACE2 are scarce as is the functional role that ACE2 plays in the lungs under normal conditions. ${ }^{68}$ This underactive role carried out by ACE2 changes towards an upregulation in some clinical states.

Evidence has shown that ACE inhibitors and angiotensin receptor blockers (ARBs) have different effects on angiotensin II which is the primary substrate of ACE2, so these agents can be expected to exert different activity on ACE2 levels. Although substantial structural homology has been demonstrated between ACE and ACE2, their enzymatic active sites are different. As a result, ACE inhibitors in clinical use do not exhibit an action to unequivocally affect the activity of ACE2. ${ }^{69}$ Diverging results regarding the effects of ACE inhibitors on ACE2 levels have been reported in experimental animal models..$^{7-73}$ By evaluating results from the animal models, inconsistent evidence on the effects of ARBs on ACE2 are disclosed. In fact, some of these experiences have reported the effect of ARBs in increasing messenger RNA expression or ACE2 protein levels in tissues ${ }^{70,74-76}$ while in 
other studies no consequence about its role was proven. ${ }^{77}$ On the other hand, a relevant number of human studies investigating the effects of RAAS inhibition on ACE2 expression have not yielded positive results. Campbell et al reported no difference in angiotensin- (1-7) production after intravenous administration of ACE inhibitors in patients with coronary artery disease. The observation that stems from this discovery is the lack of substantial evidence that ACE inhibitors have direct effects on ACE2 directed metabolism of angiotensin II. ${ }^{78}$ Luque et al obtained comparable results by analyzing angiotensin- (1-7) levels in patients who experienced hypertension and reported a lack of effect after initial treatment with the selective ACE inhibitor captopril. However, patients who were undergoing six-to-six continuous monotherapy with captopril revealed an increased level of angiotensin- (1-7). ${ }^{79}$ Furuhashi et al retrospectively analyzed a longitudinal cohort of Japanese patients with hypertension who reported increased urinary ACE2 levels among patients who were managed with long-term ARB olmesartan, compared with the group of control patients who received no medical treatment. However, this association has not been disclosed with the use of ACE inhibitor enalapril or with other ARBs such as losartan, candesartan, valsartan, and telmisartan. ${ }^{80}$

The observation that emerges in the evaluation of these conflicting results suggests that a complex mechanism exists at the basis of the RAAS responses to the pathway modulators. Another point that reinforces the lack of definitive evidence from human studies, thus lifting the veil of uncertainty, concerns the results provided by preclinical models that may not be readily noted in physiological conditions. This point is clearly emphasized in the study of Furuhashi et al in which the effects on ACE2 after administration of RAAS inhibitors should not be interpreted as uniformly applicable data because the response to therapies within a given drug class was also different. ${ }^{80}$

A precise observation concerns the plasma level of ACE2 which may not be a reliable indicator of the activity of the integral structured form in the membrane. In fact, ACE2 is released from the membrane by a process that appears to be supported by a separate regulation mediated by an endogenous inhibitor. ${ }^{81}$ Another important observation concerns the degree of expression and biological relevance of ACE2 which is not homogeneous as it may vary according to the type of tissue and the clinical condition. Unfortunately, our knowledge sustained by solid data supporting the effects of ACE inhibitors, ARBs, and other RAAS inhibitors on lung-specific expression of ACE2 in animal and human experimental models is inconsistent. Furthermore, even assuming that RAAS inhibitors can modify the levels or activity of ACE2 in the target microcirculation; there is no substantial clinical data proving the involvement of RAAS inhibitors in facilitating the interaction of the spike protein of the SARS-CoV-2 with ACE2. Further studies on ACE2 receptor mechanics need to be undertaken in humans as they would serve to better define the distinctive interaction between SARS-CoV-2 and the RAAS network.

\subsection{RAAS Blockers in SARS-CoV-2 infection. Potential for Benefit or Harm?}

The biomolecular mechanisms that regulate the interaction between SARS-CoV-2 and ACE2 lead not only to the initial entry of the virus into the host cell via ACE2 but also induce a subsequent downregulation. The crucial effect of downregulation concerns the lack of protective effect on organs exerted by ACE2. No hypothesis has ever demonstrated that the continuous activity of angiotensin II may be partly responsible for organ damage in patients with Covid-19.82,83 SARS-CoV-2 saturating the ACE2 involved in the binding with the spike leads to the subsequent down-regulation of the fullness of ACE2 receptors in host cells' surface. ${ }^{47}$ In the early stage of SARS-CoV-2 infection, viral infection and replication work together to decrease membrane ACE2 expression. The initial infiltration of neutrophils was subsequently observed in response to bacterial endotoxin which can be induced by the down-regulation of ACE2 activity in the lungs. ${ }^{84}$ Under these conditions, an unconstrained accumulation of angiotensin II with local RAAS activation occurs. Liu et al studied a small series of patients with Covid-19 who reported high plasma levels of 
angiotensin, which were consequently related to a higher total viral load and the degree of lung damage. ${ }^{83}$ Figure 6

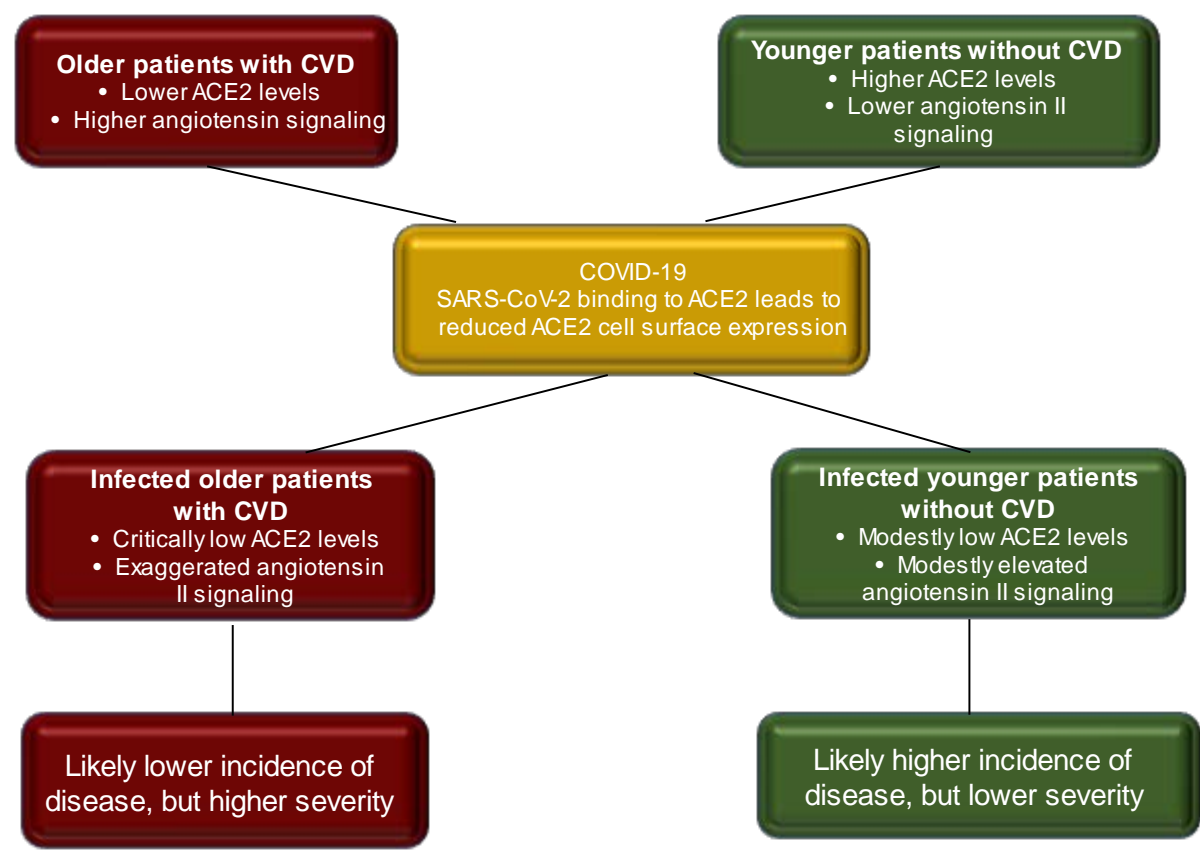

Figure 6. Depict of the inflammatory profile of Covid 19 patients before and after Coronavirus SARS Cov2 infection. The scheme reveals the occurrence of two different degrees of disease in the investigated populations.

A dysregulation of ACE2 can theoretically also lead to decreased cardioprotection in the context of myocardial involvement following pulmonary and circulatory haemodynamic compromise in patients who develop Covid-19 with severe critical conditions. ${ }^{85,86}$ In severe forms of Covid 19 with a course characterized by grave clinical deterioration preceding death, high levels of markers of myocardial injury were revealed. ${ }^{87}$ These markers underwent a rapid increase in parallel with worsening clinical conditions. ${ }^{60}$ After all, the cardiotropicity of many viruses has been reported confirming that very high viremia associated with a wide range of infectious agents can be responsible for subclinical viral myocarditis.

ACE2 is involved with a well-recognized role in myocardial recovery and injury response, as reported in the study by Oudit et al in which autopsy findings of patients who died from SARS were examined. In 35\% of the heart samples studied, the authors recorded the presence of viral RNA, which was related to a reduced expression of the ACE2 protein. ${ }^{88}$ In support of this study, it has been reported that in human explanted hearts with dilated cardiomyopathy the administration of recombinant ACE2 leads to a normalization of angiotensin II levels..$^{89}$

On the basis of this evidence, numerous randomized studies have been designed, the aim of which is to verify whether the administration of a recombinant ACE2 protein can be useful in restoring the balance of the RAAS network and therefore is potentially able to prevent the damage of organ (ClinicalTrialgov number, NCT04287686). In addition, two ongoing RCTs have been designed on the administration of losartan in the treatment for Covid-19 in the non-hospitalized patient group (NCT04311177) to patients requiring hospitalization (NCT04312009). Patients enrolled in these RCTs had not received prior medical treatment with the administration of a RAAS inhibitor. 
The topic is controversial with a large number of studies that reported the evidence of ACE2 expression on endothelial cells. 28,38;90-92 ACE 2 is expressed in several organs, including the lung, heart, kidney, and intestine, but endothelial cells also have ACE2 on their surface.

In vitro experiments have reported that SARS-CoV-2 can directly infect organoids in engineered human blood vessels. ${ }^{93}$ However, this evidence does not prove that the vascular disorders in COVID-19 are due to the involvement of the endothelial cells by the virus.

Ackerman et al reported that vascular angiogenesis, either intussusceptive or germinative, differentiated the pulmonary pathobiology of patients who had COVID-19 from these of alike severe influenza virus-related infections. Given this background, investigators examined 7 lungs of patients who died caused by COVID-19 that were compared with those who died for acute respiratory distress syndrome (ARDS) secondary to influenza A (H1N1). These autopsy specimens were separated to 10 age-matched, uninfected control lungs.

Several points of Ackerman's study deserve detailed assessments. First, immunohistochemical analysis data concerning ACE expression in controls of patients without lung infection suggested for ACE2 expression in alveolar epithelial cells $(0.053 \pm 0.03)$ and capillary endothelial cells $(0.066 \pm 0.03)$. In contrast, in the lung findings of patients with COVID-19 and those with influenza A who had died for the onset of severe respiratory failure, the relative tallies of ACE2-positive revealed a high expression of alveolar epithelial cells (relative counts of $0.25 \pm 0.14$ vs $0.35 \pm 0.15$ ) and endothelial cells (relative counts of $0.49 \pm 0.28$ and $0.55 \pm 0.11$ ), respectively. It is important to note that ACE2-positive lymphocytes were not disclosed in perivascular tissue or alveoli of the non-infected controlled lungs. However, the interaction between the ACE2 receptor and immune cells occurred in the lungs of patients with Covid-19 and in those who have experienced H1N1 infection in combination with a respiratory distress syndrome (relative counts of $0.22 \pm 0.18$ and $0.15 \pm 0.09$, respectively). ${ }^{28}$

The second major finding reported was the occurrence of a marked angiogenesis process that intervenes in patients who died for severe Covid 19. This population had consistently demonstrated intussusceptive angiogenic lung features that were significantly higher $(60.7 \pm 11.8)$ compared to those of the lungs of patients who had suffered from H1N1 infection $(22.5 \pm 6.9)$ or to those of patients without any signs of lung infection (2.1 $\pm 0.6)$. The comparison was statistically significant for both populations $(\mathrm{P}<0.001)$. With regards to the consistency of conventional germinative angiogenesis features, it was also greater in the Covid-19 population compared to the influenza population. ${ }^{28}$

The third interesting finding of this study involved a correlation between pulmonary angiogenesis and hospitalization where angiogenesis was plotted as a function of length of hospital stay. Investigators noted that the degree of intussusceptive angiogenesis was found significatively with raising duration of hospitalization $(\mathrm{P}<0.001)$. In contrast, examination of the lungs of patients with $\mathrm{H} 1 \mathrm{~N} 1$ infection revealed less intussusceptive angiogenesis without a demonstrable increase over time. A similar pattern was seen for germinative angiogenesis. ${ }^{28}$

Finally, Ackermann et al provided an evaluation of angiogenesis-related genes that was performed in patients in which associated respiratory failure occurred. Investigators using a multiplex analysis of angiogenesis-related gene expression examined 323 genes from the nCounter PanCancer progression panel (NanoString Technologies) and recorded differences between samples from patients with Covid-19 and those from patients with influenza. 69 angiogenesis-related genes were found to be differentially regulated in deceased Covid-19 patients, compared with 26 differentially regulated genes that were disclosed in patients who experienced the H1N1 infection. The relevant finding was that 45 genes shared changes in expression. ${ }^{28}$

A potential greater ACE2 receptor expression caused by induced angiogenesis, can lead to a substantially higher interplay of SARS Cov2 with the receptor so as to implement 
the ACE2 power in sustaining the infection. However, other investigations have assumed the primary role in the involvement of microvascular pericytes, as these types of cells express high levels of the ACE2 receptor.90,94,95 Therefore, it is the lesion of the pericyte, from the extension of the viral infection, the determining cause for inducing endothelial dysfunction.

In particular, Mc Cracken et al investigated ACE2 expression in human endothelial cells (ECs) and the ability of SARS-CoV-2 to infect the endothelium by analyzing transcriptomic and epigenomic data on ECs. Viral proteins combined with ECs were studied in vitro using an analysis of RNA sequencing. The ENCODE has allowed the genetic evaluation of infected ECs of different tissues including arterial, venous, and microvascular beds, in comparison with epithelial cells from respiratory, gastrointestinal, and skin sources. Investigators recorded a very low or no basal ACE2 expression in ECs compared with epithelial cells. Moreover, they observed that in vitro exposure of ECs to inflammatory cytokines were increased in the plasma of patients with severe COVID-19.95 This condition failed to upregulate ACE2 expression. Single-cell RNA sequencing of human organ donor arts revealed that, while ACE2 sequence reads were abundant in pericytes, it was rare in ECs. ${ }^{96}$ Although there was an unusual endothelial ACE2 expression, however contamination from adherent pericyte fragments was possible to determine a common confounder in vascular single-cell RNA sequencing data. ${ }^{97}$ Evidence suggested that there was a scarce occurrence of ACE2 transcripts in human heart ECs and is likely determined by pericyte contamination. Investigators exposed the ECs to SARS-CoV-2 and observed that replication levels were extremely low, even after the ECs were exposed to very high concentrations of the virus compared to more permissive VeroE6 cells. The observed low levels of SARS-CoV-2 replication in ECs were due to viral entry via an alternative pathway to the ACE2-dependent one. This non-Ace receptor-mediated entry was attributable to exposure of greater concentrations of the virus. Data reported proved that direct endothelial infection by SARS-CoV-2 is not likely to occur. The endothelial damage disclosed in patients with severe COVID-19 and in critically ill conditions were more likely secondary to infection of neighboring cells. Other mechanisms, including immune cells, platelets, and complement activation, and circulating pro-inflammatory cytokines were implicated in endothelial damage. This evidence was supported by current achievements proving that plasma from critically ill and convalescent patients with COVID-19 lead to EC cytotoxicity. ${ }^{98}$

\subsection{Other molecules (mediators) affecting angiogenesis during SARS Cov2 infection}

Reports have demonstrated the expression of neuropilin receptors ${ }^{53,56-59}$ and TMPRSS2, ${ }^{99}$ thus suggesting a viral infection of endothelial cells.

Investigators have learned that neuropilin 1 , a type 1 membrane protein, was characterized by being highly expressed among Xenopus frogs, chicken, and mice. The extracellular component of NRP-1 was composed of three distinctive domains, each of which was involved in molecular and/or cellular interactions. Evidence suggested that in mammals, NRP-1 was expressed in the cardiovascular system, the nervous system, and in the limbs at specific phases of development. Studies performed on chimeric embryos revealed several morphological abnormalities such as excess capillaries and blood vessels, dilation of blood vessels, malformed heart as well as ectopic sprouting and defasciculation of nerve fibers. These kinds of abnormalities experienced in chimeric embryos suggested that NRP-1 has several functions in embryonic morphogenesis. ${ }^{56-58}$

Gerhardt et al disclosed the role of NRP-1 in central nervous system germinative angiogenesis that was mediated by binding to the isoform VEGF165 (Vascular Endothelial Growth Factor). The latter led to the stimulation of angiogenesis and was indispensable for the development of cerebral vessels in the mouse.

Targeted inactivation of the NRP1 receptor can lead to abnormalities in the blood flow capable of influencing the dynamics of SARS CoV2 infection. Therefore, blood fluid 
dynamics plays a crucial role in the effects of SARS CoV2 infection. The vascular neoformation and the presence of flow changes can induce both stabilization of the infection in the primary localization and an acceleration in the propagation of the virus making it potentially the determining factor in the dynamics of SARS CoV2 infection. Jones et al revealed that the loss of NRP1 function rather than the induced dynamic flow change was the cause of the altered capillary plexus geometry. Evidence was in favour of vessel remodeling defects which occurred concomitantly with the onset of blood flow. A genetic alteration in neuropillin1 mutants led mainly to a deficiency related to endothelial cell migration rather than replication. The inadequacy of migration of endothelial cells was therefore the main cause of the altered blood flow dynamics. ${ }^{57}$

Aspalter et al worked on VEGF and Dll4 / Notch signaling, which cooperate in a negative feedback circle. VEGF and DIl4 / Notch signaling play a central role in the specified endothelial tip and stalk cells to oversee the function of the vessels. So, VEGF and Dl14 / Notch were active in sprouting angiogenesis by guiding the growth of blood vessels in healthy and diseased tissues. Investigators discovered the key endothelial function of NRP1, which abolished the stalk-cell phenotype by restricting the activation of Smad2 / 3 through the function of Alk1 and Alk5. The evidence first revealed that Notch downregulates Nrp1, thereby relieving the inhibition of Alk1 and Alk5, thus driving stalk-cell behavior. Second, the authors disclosed that the heterogeneity between neighboring endothelial cells determined by the lateral Dll4 / Notch feedback circle used NRP1 levels as the pivot, which in turn warranted a distinctive reactivity to TGF - $\beta$ / BMP signaling. 58

More recently two reports focused the attention on the specific role of NRP1 as the key factor implicated in the viral trophism. Canuti-Castelveteri et al evaluated the role of nuropillin1 in the tissue tropism because NRP1 works like a cofactor on the surface of the host cell in promoting easier interaction between the viral particle and virus receptor. Authors suggested that NRP1 significantly reinforces SARS-CoV-2 infectivity working to bind furin-cleaved substrates. This action was prevented with the use of monoclonal blocking antibody against NRP1. In the case of mutations induced in SARS-CoV-2, undergoing a modification in the furin cleavage site, the infectivity of SARS Cov 2 was not potentiated by neuropillin1. Human autopsies performed on the olfactory epithelium after Covid 19 provided pathological findings in which SARS-CoV-2 infected NRP1-positive cells were present in the nasal cavity. The reported data added important information on the infectivity of SARS-CoV-2 cells in the first stage and defined a potential target for the development of antiviral drugs. ${ }^{59}$

Daily et al found that the host furin protease recognizes an attachment site on the viral protein $S$ that cleaves the full-length precursor of $S$ glycoprotein into two associated polypeptides: S1 and S2. This interaction facilitating the cleavage of protein S led to the creation of a polybasic Arg-Arg-Ala-Arg carboxy-terminal sequence on S1. This sequence conformed to a C-end rule (CendR) motif which has the characteristic of selectively binding NRP1 and NRP2 to cell surface receptors. The relevant data that emerged was the selectivity of the CendR motif in S1 which directly linked NRP1. Once the blocking of this interaction has been carried out using RNA interference or through selective inhibitors, a reduced entry of SARS-CoV-2 can be obtained which results in reduced infectivity. Therefore, NRP1 has been shown to act as a host factor for SARS-CoV-2 infection and could potentially provide a selective therapeutic target to counter COVID-19.53 Figure 7 
A

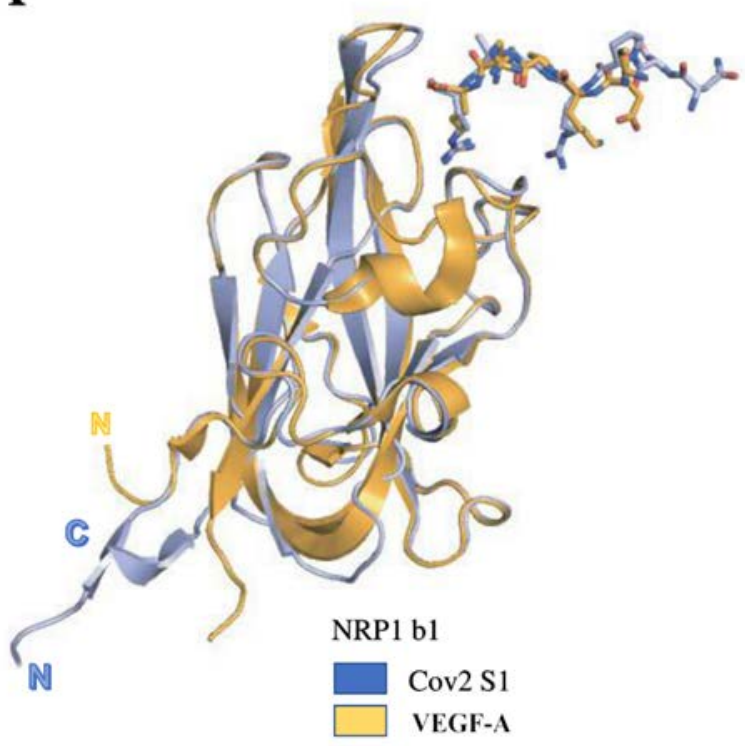

B

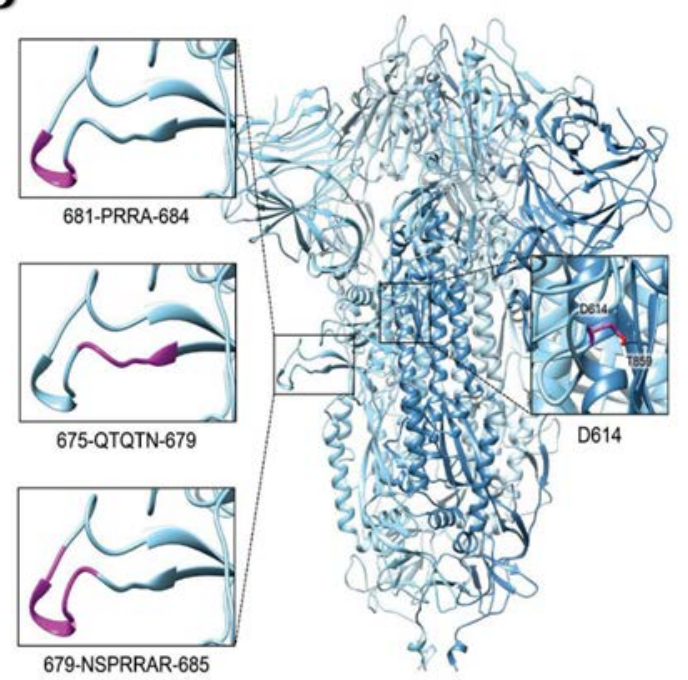

RMSD $=1,1 \mathrm{~A}$

Figure 7. A: Depicts NRP1 b1-S1 CendR peptide complex superposed with NRP1 b1- VEGF-A fusion complex (based on PDB ID: 4DEQ†). Bound peptides are disclosed in stick representation. B: Structure of the SARS-CoV-2 spike trimer, based on PDB 6ZGEtt, in which we modelled the cleavage loop using SWISS-MODEL. Transmembrane serine protease 2 (TMPRSS2) and TMPRSS13 cleaves the spike shortly after binding ACE2. Host cell surface proteases such as TMPRSS2 and TMPRSS13 cleave the full-length spike protein (S0) converting it to its S2 site through a complex mechanism mediated by the selective function of the host's furin. Activation of $S$ glycoproteins of SARS CoV-2 (SARS-2-S) by these surface proteases requires processing of the S1/S2 cleavage loop, in which both the furin recognition motif and extended loop length proved critical.

Abbreviations: RMSD, root mean square deviation; VEGF-A, Vascular Endothelial Growth Factor; others abbreviations in previous figures.

From Wrobel AG, et al. Nat Struct Mol Biol. 2020; 27(8):763-767 and Waterhouse A et al. Nucleic Acids Res. 2018; 46(W1):W296-W303. thttps:/www.rcsb.org/structure/4DEQ; +thttps://www.rcsb.org/structure/6zge

Hofmann et al proved that the serine protease TMPRSS2 was employed after the engagement of ACE2 receptor by SARS-CoV-2 and it worked as S protein priming and they disclosed that SARS-CoV-2 spread also depends on TMPRSS2 activity. The role of TMPRSS2 was pivotal and synergistic with furin-mediated pre-cleavage at the S1 / S2 site in infected cells, which could ultimately encourage subsequent SARS Cov-2 dependent TMPRSS2 entry into target cells. This mechanism can be compromised with a TMPRSS2 inhibitor camostat mesylate which is approved for clinical use in Japan. This substance has potentially an increased antiviral activity leading to a blockage of viral entry and it might constitute an off-label treatment option. ${ }^{45}$

\section{The pathoanatomic alteration of the endothelium and SARS CoV-2 infection}

Investigations on autopsy findings of patients who died after COVID-19 have helped to clarify whether SARS-CoV-2 can directly infect the endothelium. Bryce at al reported the first 100 COVID-19-positive autopsies performed at the Mount Sinai Hospital in New York City noticing the presence of large pulmonary emboli in six cases. Furthermore, the authors found that diffuse alveolar damage occurred in over $90 \%$ of cases and that microthrombi were discovered as typical lesions in multiple organs including the brain. Hemphagocytosis was another peculiar patho-anatomic lesion. Electron microscopic tests 
revealed the presence of the virus in the samples, and laboratory results from the COVID19 cohort revealed high levels of inflammatory markers, abnormal clotting values, and elevated cytokines IL-6, IL-8, and TNF $\alpha .{ }^{100}$

In the autopsy checks by Ackerman et al an interesting finding shared the histological picture in the peripheral lung both of patients who died from respiratory diseases associated with Covid-19 or those who had influenza-associated respiratory failure. Both showed diffuse alveolar damage with perivascular T cell infiltration. However, the patients who had suffered from Covid-19 disclosed well-defined and characteristic pulmonary vascular changes. Consistent histopathological evidence suggested the occurrence of a severe endothelial lesion associated with the presence of intracellular viruses and destroyed cell membranes. An analysis of the pulmonary vessels of patients with Covid-19 revealed widespread thrombosis with microangiopathy. Damage generated by alveolar capillary microthrombi was 9 times more prevalent in patients with Covid-19 and patients with influenza, compared to healthy lung findings $(\mathrm{P}<0.001)$. The data that differentiated the findings of patients who died from Covid 19 to that for influenza-associated respiratory failure concerned the greatest amount of growth of new vessels in the lungs of patients with Covid-19. This conspicuous microvascular growth was mainly attributable to a mechanism of intussusceptive angiogenesis and was 2.7 times as high as that of the lungs of patients with influenza $(\mathrm{P}<0.001) .28$

Histopathology revealed in all lung specimens from the Covid-19 autopsies a spread alveolar injury that may be disclosed as focal with only mild interstitial edema or occurred with homogeneous fibrin accumulation associated with marked interstitial edema and early intraalveolar organization. Necrosis of alveolar lining cells, pneumocyte type 2 hyperplasia, and linear intraalveolar fibrin deposition were observed in either focal or diffuse lesions. The difference was noted in specimens of the influenza group in which florid diffuse alveolar damage with massive interstitial edema and extensive fibrin deposition occurred in all cases. In addition, in some cases, specimens may present focal organizing and resorptive inflammation. These changes were suggestive of the substantially higher weight of the lungs from patients who died from influenza. 28

A cytological evaluation revealed differences between the autopsy findings of patients who died from influenza compared to those who died from Covid 19. In the lungs from patients with Covid-19 and patients with influenza CD3-positive T cells $(26.2 \pm 13.1$ for Covid-19 and $14.8 \pm 10.8$ for influenza). These values were referred to $200-\mu \mathrm{m}$ radius of precapillary and postcapillary vessel walls in 20 fields of examination per patient. With the same field size, authors found more relevant amount of CD4-positive T cells in lungs from patients with Covid-19 than in lungs from patients with influenza (13.6 $\pm 6.0 \mathrm{vs}$. $5.8 \pm 2.5, \mathrm{P}=0.04)$, whereas the amount of $\mathrm{CD} 8$-positive $\mathrm{T}$ cells was also significant $(5.3 \pm 4.3$ vs. 11.6 $\pm 4.9, \mathrm{P}=0.008$ ). The number of neutrophils (CD15 positive) were significantly lower numerous adjacent to the alveolar epithelial lining in the Covid-19 group than in the influenza group $(0.4 \pm 0.5$ vs. $4.8 \pm 5.2, \mathrm{P}=0.002) .{ }^{28}$

Schaefer et al studied in situ expression of SARS-CoV-2 in airways and lungs obtained at autopsy of seven autopsy cases (male, $\mathrm{N}=5$; female, $\mathrm{N}=2$ ) with confirmed COVID-19 infection. The use of reverse transcriptase-polymerase chain reaction (RTPCR)-validated SARS-CoV-2 infection and the detection of viral particles from autopsy cases were evaluated using a rabbit polyclonal antibody against SARS Nucleocapsid protein in correlation with clinical parameters. Chest imaging suggested a widespread airspace disease occurred in all patients. Histologic examination revealed an acute diffuse alveolar damage (DAD) in 5 cases while 2 cases developed preferentially organized alveolar injuries. Among five patients acute diffuse alveolar damage SARS-CoV-2 was located in pulmonary pneumocytes while in all cases damage involved ciliated airway cells. In two cases viral particles were identified also in the upper airway epithelium. Interestingly, in two patients with organizing DAD, SARS CoV-2 was not discovered in lungs or airways, and in these cases, investigators did not reveal endothelial cell infection. This evidence strongly suggested that SARS-CoV-2 infection, involving epithelial cells in lungs 
and airways of patients with COVID-19 who progressed toward respiratory failure, can be identified during the acute stage of lung injury and was absent in the organizing stage. ${ }^{101}$

Varga et al found the pathological modifications of the endothelium exposed to SARS CoV-2 infection which involved patients of different ages and with multiple comorbid conditions. The authors described the case of a recipient of a renal transplant with coronary artery disease and arterial hypertension. In the patient, the deterioration of clinical conditions due to Covid 19 required the use of mechanical ventilation. On the eighth day, after being admitted to the ICU, the evolution towards a severe form of multisystem organ failure had resulted in death. The use of electron microscopy performed on postmortem autopsy findings highlighted the presence of viral inclusion structures in endothelial cells in the transplanted kidney (figures A, B). The histological analysis showed the accumulation of inflammatory cells associated with endothelium. The histological changes involved many tissues including apoptotic bodies, in the heart, the small bowel (figure C), and lung (figure D). The lung experienced a remarkable accumulation of mononuclear cells with characteristic involvement of most small lung vessels that appeared congested. 102

Severe endothelitis occurred in patients with comorbidities such as diabetes, arterial hypertension, and obesity. A severe and progressive respiratory failure due to negative evolution of COVID-19 led these patients to hospitalization in the ICU. Subsequently, the impairment of the clinical condition may lead to multi-organ failure. Mesenteric ischaemia generally is caused by thrombosis and endothelitis requiring prompted removal of necrotic small intestine. From a cardiocirculatory point of view, severe right heart failure may occur as an evolutionary progression of left ventricular compromise related to consequent ST-segment elevation and myocardial infarction. The progressive evolution of this complication was toward a cardiac arrest. Histological post-mortem analysis recorded a high grade of lymphocytic endotheliitis in lung, heart, kidney, and liver as well as a rapid progression towards necrosis of liver cell. In addition, pathoanatomic damage with evidence of myocardial infarction was reported, however without any prove of pathoanatomic injuries related to lymphocytic myocarditis. The small intestine was investigated and the histology revealed endotheliitis of the submucosal vessels. ${ }^{102}$

Delorey et al worked donors who died of COVID-19 producing both single-cell atlases from 24 lung, 16 kidney, 16 liver, and 19 heart autopsy tissue samples and spatial atlases of 14 lung samples. With the use of integrated computational analysis, investigators found the occurrence of substantial remodelling in the lung epithelial, stromal, and immune sections. In these three compartments, evidence suggested multiple tracks of failed tissue regeneration, including defective alveolar type 2 differentiation and expansion of fibroblasts and putative TP63+ intrapulmonary basal-like progenitor cells. ${ }^{103}$ The authors enriched viral RNAs in phagocytic mononuclear and endothelial lung cells, which induced host-specific programs of response to infection. For example, investigators differentiated lung regions with and without viral RNA expression so that spatial analysis in the lung distinguished host inflammatory responses. Instead, through the non-spatial analysis performed on other tissue atlases, transcriptional alterations were recorded in multiple cell types in the heart tissue of donors with COVID-19. Based on genome-wide association studies of COVID-19, a mapping of the cell types and genes involved was performed and correlated with disease severity. This study highlighted fundamental data that clarify the biological effect of severe SARS-CoV-2 infection by highlighting the systemic character of the infection involving the whole body suggesting a fundamental step towards new treatments. ${ }^{103}$

Lindner et al revealed the existence of SARS-CoV-2 in the myocardial tissue from autopsy of patients who died. The objective of investigation was to reveal a possible cardiac response to the infection ${ }^{104}$ by working at discovering the incidence of SARS-CoV-2 positivity in cardiac tissue employing selective immuno-investigation on CD3+, CD45+, and CD68+ cells in the myocardium. In addition, they evaluated gene expression of tumor 
necrosis growth factor $\alpha$, interferon $\gamma$, chemokine ligand 5, as well as interleukin- $6,-8$, and -18 in myocardial tissue of patients infected with SARS CoV-2. The study included 39 consecutive autopsy cases with median (interquartile range) age of patients that was 85 (7889 ) years, of which $59.0 \%$ were women. The presence of SARS-CoV-2 was recorded at a rate of $61.5 \%$ of patients and viral load with a concentration of 1000 copies per $\mu \mathrm{g}$ of RNA was reported at a rate of $41.0 \%$, respectively. As regard cytokine response, the panel disclosed the existence of 6 proinflammatory genes that were increased in 16 patients who experienced SARS-CoV-2 in the heart compared to those 15 patients without any localization of infection. The comparison between 15 patients without infection located in the heart and 16 patients who recorded more than 1000 copies revealed the absence of inflammatory cell infiltrates or differences in leukocyte numbers per high power field. The results of this study performed on autopsy cases could suggest the presence of SARS-CoV2 within the myocardium. Although it might speculate a potential response to SARS-CoV2 infection that could be produced in cases with higher virus load vs no virus infection; however, there is no clear evidence that the presence of the virus in the myocardium leads to an influx of inflammatory cells. Future investigations should be directly focused on evaluating the long-term consequences of cardiac involvement and influx of inflammatory cells ${ }^{104}$ Table 1

Table 1. Studies reporting pathoanatomic alteration in SARS Cov2 infection.

\begin{tabular}{|c|c|c|c|c|c|}
\hline First Author/Year Ref & Type of Study & $\begin{array}{c}\text { Number of } \\
\text { Patients } \\
\end{array}$ & $\begin{array}{c}\text { Mean } \\
\text { Age, yrs }\end{array}$ & Autopsy (n) & Findings \\
\hline $\begin{array}{l}\text { Bryce et al } \\
2021(100)\end{array}$ & OS & 100 & $\begin{array}{l}29 \text { to } 94 \text { years } \\
\text { (Median 68) }\end{array}$ & $\begin{array}{c}\text { Lung } 99 \\
\text { Heart } 97 \\
\text { Spleen } 86 \\
\text { Lymphnodes } 60 \\
\text { Kidney } 94 \\
\end{array}$ & $\begin{array}{c}82 \text { cases DAD ; } \\
\text { Hemphagocytosis } \\
\text { Higher cytokines IL-6, IL-8, and TNF } \alpha \text {. }\end{array}$ \\
\hline $\begin{array}{l}\text { Ackerman et al } \\
2020(28)\end{array}$ & OS & $\begin{array}{c}14 \\
\text { SARS Cov } 27 \\
\text { H1N1 } \\
7\end{array}$ & $\begin{array}{l}68 \pm 9.2 \text { years (female) } \\
80 \pm 11.5 \text { years (male) }\end{array}$ & Lung 14 & $\begin{array}{c}\text { Alveolar capillary microthrombi } 9 \\
\text { times more in SARS Cov2 } \\
\text { Higher CD3, CD4 and CD-8 positive T } \\
\text { cells in SARS Cov2 } \\
\text { Lower neutrophils (CD15) }\end{array}$ \\
\hline $\begin{array}{l}\text { Schaefer et al } \\
2020(101)\end{array}$ & OS & 7 & $\begin{array}{l}50 \text { to } 77 \\
\text { (Median } 66 \text { ) } \\
\text { Male } 16 \\
\text { Female } 23\end{array}$ & Lung 7 & $\begin{array}{c}5 \text { cases diffuse DAD ; } 2 \text { cases alveolar } \\
\text { injuries. SARS-CoV-2 infection } \\
\text { involving } \\
\text { epithelial lung cell in acute phase } \\
\text { No endothelial cell infection }\end{array}$ \\
\hline $\begin{array}{l}\text { Varga et al } \\
2020(102)\end{array}$ & OS & 3 & $\begin{array}{l}58 \text { to } 61 \text { years } \\
\text { (Median 63) }\end{array}$ & $\begin{array}{l}\text { Kidney } 2 \\
\text { Lung } 2 \\
\text { Heart } 1 \\
\text { Liver } 1 \\
\text { Intestin } 2 \\
\end{array}$ & $\begin{array}{l}\text { Lymphocytic endotheliitis in lung, } \\
\text { heart, kidney, and liver. } \\
\text { Apoptotic bodies in the heart } \\
\text { Mononuclear cells in lung }\end{array}$ \\
\hline $\begin{array}{l}\text { Delorey et al } \\
2021(103)\end{array}$ & OS & 32 & $\begin{array}{c}30 \text { to } 89 \text { years } \\
\text { Male } 20 \\
\text { Female } 12\end{array}$ & $\begin{array}{l}\text { Kidney } 16 \\
\text { Lung } 24 \\
\text { Heart } 19 \\
\text { Liver } 16\end{array}$ & $\begin{array}{l}\text { Higher viral RNAs in phagocytic } \\
\text { mononuclear and endothelial lung } \\
\text { cells. Transcriptional alterations in } \\
\text { multiple cell types in the heart tissue. }\end{array}$ \\
\hline $\begin{array}{l}\text { Lindner et al } \\
2020(104)\end{array}$ & Prospective & 39 & $\begin{array}{l}78 \text { to } 89 \text { years } \\
\text { (Median } 68 \text { ) } \\
\text { Male } 16 \\
\text { Female } 23\end{array}$ & Heart 39 & $\begin{array}{l}\text { SARS-CoV-2 infects directly the } \\
\text { myocardium } \\
\text { Absence of inflammatory cell infiltrates } \\
\text { in patient with SARS Cov2 infection. } \\
\text { Higher cytokine response }\end{array}$ \\
\hline
\end{tabular}

Abbreviations : DAD, diffuse alveolar damage ; other abbreviations in previous figures 


\section{The role of the endothelium in infection: direct or vicarious?}

Thrombosis and microangiopathy are relevant in lung tissue infected with SARS CoV-2. An analysis of the pulmonary vasculature of the lungs in the Covid-19 patients who succumbed to respiratory complications revealed the prevalence of thrombi in pulmonary arteries with a diameter of $1 \mathrm{~mm}$ to $2 \mathrm{~mm}$ at the level of precapillary vessels, without complete luminal obstruction. Similar pathoanatomic alterations were common in the autopsy surveys of patients infected with the influenza A virus. Nonetheless, a distinctive feature between the two pathogens located in pulmonary vasculature was the formation of thrombi in the capillary alveoli. Although they were disclosed in both biopsy findings, fibrin thrombi occurred 9 times more commonly in patients with Covid-19 compared to influenza. Contrary to the arteriolar system, the venular one seems more affected by the infection sustained by Virus A with a statistically higher incidence of intravascular thrombi in postcapillary venules of less than $1 \mathrm{~mm}$ in diameter. These histologic findings were supported by three-dimensional micro-CT of the pulmonary specimens suggesting that the lungs from patients with Covid-19 and influenza showed nearly total occlusions of precapillary and postcapillary vessels. ${ }^{28}$

The unresolved focal question is whether SARS CoV2 can replicate in endothelial cells of the new angiogenic process and whether the more or less distorted neo-architecture can be considered a factor influencing the replication.

The findings by Schimmel et al go against the trend and the researchers suggest that in vivo infection of endothelial cells by SARS-CoV-2 is unlikely. They speculate that endothelial infection can occur in the condition defined as basolateral infection which occurs only if the adjacent lung epithelium is denuded. Another possibility includes the potential infection of the endothelium when a high viral load is present in the blood, a condition that the investigators define as apical infection. In the scenario described, while the occurrence of SARS-CoV-2 infection of the endothelium is conceivable, it does not contribute to viral amplification. ${ }^{105}$ However, the central role of endothelial cells in SARS-CoV-2 infection plays a key role in the pathogenesis of the infection. The progression of infection from the pulmonary epithelium with the involvement of the adjacent infected endothelium favored the development of a pro-inflammatory response to SARS-CoV-2. ${ }^{105}$

An interesting finding was provided by examining the microvascular architecture of the lungs of patients with COVID-19. The autopsies of the lungs of patients with COVID-19 experienced distorted vascularity with structurally deformed capillaries. This chaotic angiogenesis revealed the presence of capillaries which had sudden changes in caliber and the presence of pillar intussusception within the capillaries. Ultrastructural damage of the endothelium was disclosed on electron microscopy examination of the endothelium within which the presence of intracellular SARS-CoV-2 was observed. In these pathoanatomical circumstances, the investigators did not rule out the possibility of identification of the virus in the extracellular space as well..$^{28}$

\section{Comment and Conclusion}

Although the studies reporting autopsy findings were scarce in number, the vascular features identified were consistent with the presence of distinctive cardiac, pulmonary vascular, and endothelial pathobiological features in these cases of Covid-19. ${ }^{28,100-104}$

Important evidence for the understanding of endothelial damage and angiogenesis was provided by the study of autopsy lung findings. The lungs from the patients who suffered from COVID 19 revealed morphologic patterns of diffuse alveolar damage and infiltrating perivascular lymphocytes. Reports have disclosed three distinctive angiocentric features of Covid-19. First, evidence has proved severe endothelial injury coupled with intracellular SARS-CoV-2 virus and disrupted endothelial cell membranes. Secondly, robust findings suggest widespread vascular thrombosis with microangiopathy and occlusion of alveolar capillaries that occurred in the lungs of patients with COVID-19. Third, 
the lungs of patients with Covid-19 remarkably revealed an increase in new vessel growth through a mechanism of intussusceptive angiogenesis. $28,106,107$ In particular intussusceptive angiogenesis in the lungs from patients with Covid-19 was characterized by new vessel growth that might have occurred by conventional sprouting or nonsprouting angiogenesis. It is important to note that the existence of a pillar or pivot crossing the lumen of the vessel was the distinctive feature of intussusceptive angiogenesis. ${ }^{108}$ These critical changes in the endothelial-lined intravascular structure, which were specific to the appearance of the intussusceptive pillar, were not visible under the light microscope but they could be easily identified by corrosion casting and scanning electron microscopy. ${ }^{28}$

Ackerman et al showed that in addition to tissue hypoxia, the greater degree of endotheliitis and thrombosis in patients' lungs who experienced Covid-19 could cause a high rate of germination and intussusception angiogenesis observed in these patients. Although, the authors suggested that the degree of intussusceptive angiogenesis in patients with Covid-19 had significantly increased with the increasing length of hospitalization, no definitive conclusions could be drawn about the presence of these lesions and the disastrous clinical evolution. ${ }^{28}$ The authors previously reported that intussusceptive angiogenesis was the main angiogenic mechanism directly implicated in the late stages of chronic lung injury. ${ }^{28}$

The clinical neurological manifestations during SARS CoV-2 infection that develop following the involvement of the vascular system responsible for cerebral circulation deserve further attention. Neurological manifestations in the course of COVID-19 infection have been reported as high as $36 \%$ in a large 226-patients cohort, with 5 cases of stroke. A pathogenetic link between Covid-19 infection and systemic hypercoagulability or prothrombotic state has been suggested.22 Other cases were associated with anti-cardiolipin and antiphospholipid antibodies. ${ }^{109}$ Cases of thrombotic neurological events have been also sporadically reported over the course of this pandemic. Wang et al. reported a series of 5 COVID-19 patients with cerebral vessel occlusion treated with mechanical thrombectomy. In this series, patients' investigations demonstrated a large clot burden with fragmentation and multiple territories involvement. In all these cases an underlying disturbance of the coagulation profile was demonstrated..$^{17}$ A case of acute ischemic stroke from a large floating thrombus within the common carotid artery in a patient with no specific past medical history or risk factors was also recently described. MRI showed a large thrombus adherent to a thin atheromatous plaque but failed to demonstrate ulceration, hemorrhage, or signs of arteritis. However, a hypercoagulable state with elevated Ddimer and CRP was shown, corroborating the hypothesis of a thrombotic proclivity triggered by the infection-related inflammatory response and explaining the occurrence of thrombi in relatively unusual sites..$^{18}$ Interestingly, Fara et al. reported 3 cases of stroke secondary to large vessel thrombosis without occlusion even in the setting of a mild infection with COVID-19, in which the inflammatory response is supposedly expected to be weaker. However, they still found a significant systemic hypercoagulability with elevated CRP and D-Dimer. ${ }^{19}$

In our case, symptomatic large-vessel arterial thrombosis occurred in absence of a significant alteration of the coagulation profile or thrombophilic state and without a significant laboratory-demonstrable inflammatory response. No atheromatous disease was demonstrable. This case might support the emerging hypothesis of a direct effect of SARS$\mathrm{CoV}-2$ on plaque stability and endothelium function. ${ }^{110}$ Viral particles have been identified within the endothelium with accompanying endotheliitis and apoptosis. Viral-mediated endothelial disruption was considered responsible for endothelial dysfunction ${ }^{102}$ and might lead to local thrombus formation even independently on the systemic pro-inflammatory effect of the infection. However, an isolated, direct effect of the pathogen in the context of such a systemic infection is difficult to discern and there is no direct proof of viral-related endothelial damage in this case as we could not perform histological examinations. 
Finally, the role of ACE2 is fundamental in mechanisms leading to endothelial dysfunction. ACE2 is an integral membrane protein that appears to be the host-cell receptor for SARS-CoV-2. ${ }^{49,111} \mathrm{~A}$ significantly higher number of ACE2-positive cells in the autopsy of lungs from patients with Covid-19 has been revealed. Histopathological evidence proved higher numbers of ACE2-positive endothelial cells and crucial modifications in endothelial morphology and this finding is a further confirmation for a steady head role of endothelial cells in the vascular phase of Covid-19. Typical disruption of intercellular junctions, cell swelling, and a loss of contact with the basal membrane were observed in endothelial cells from selected samples of patients with Covid-19. Several studies testified the presence of the SARS-CoV-2 virus within the endothelial cells suggesting that direct viral effects, as well as perivascular inflammation, may lead to a critical contribution to cause the endothelial injury. ${ }^{28,102}$

Author Contributions: Conceptualization, F.N.; methodology, F.N, SS.AS.; software, SS.AS.; validation, F.N, SS.AS.; formal analysis, F.N, SS.AS; investigation, F.N.; data curation, F.N. and SS.AS.; writing - original draft preparation, F.N.; writing - review and editing, F.N, S.S.A.S.; visu-alization, F.N. and SS.AS.; supervision, F.N and SS.AS. All authors have read and agreed to the published version of the manuscript.

Funding: This research received no external funding.

Institutional Review Board Statement: Not applicable.

Informed Consent Statement: Not applicable.

Data Availability Statement: Not applicable.

Conflicts of Interest: The authors declare no conflict of interest

\section{Abbreviations}

ACA anterior cerebral artery

ACE1 angiotensin I-converting enzyme,

ACE2 angiotensin-converting enzyme 2,

Ang-II angiotensin II,

Ang-Iangiotensin I,

Ang 1-7 angiotensin 1-7,

ARDS severe acute respiratory distress syndrome,

ARBs angiotensin II receptor blockers,

AT1R angiotensin type 1 receptor,

CoVs coronaviruses,

CAD coronary artery disease,

CVD cardiovascular disease,

$\mathrm{CatB} / \mathrm{L}$ cathepsin $\mathrm{B} / \mathrm{L}$,

COVID-19 coronavirus disease 2019,

CT computed tomography,

DIC disseminated intravascular coagulation,

EC endothelial cell

$\mathrm{Kb}$ kilobases,

ICU intensive care unit,

IL Interleukin,

MCA middle cerebral artery,

MI myocardial infarction,

MRI magnetic resonance,

NRP neuropilin, 
PE pulmonary embolism ,

RBD receptor binding domain,

RMSD root mean square deviation

SARS-CoV severe acute respiratory syndrome coronavirus,

SARS-CoV-2 severe acute respiratory syndrome coronavirus 2 ,

S spike,

TMPRSS2 transmembrane serine protease 2,

VEGF-A Vascular Endothelial Growth Factor;

VTE venous thromboembolism,

WHOWorld Health Organization,

\section{Reference}

1. Cheng VCC, Lau SKP, Woo PCY, Yuen KY. Severe acute respiratory syndrome coronavirus as an agent of emerging and reemerging infection. Clin Microbiol Rev. 2007 ;20(4) :660-694. Doi :10.1128/ CMR.00023-07

2. Cowan LT, Lutsey PL, Pankow JS, Matsushita K, Ishigami J, Lakshminarayan K. Inpatient and outpatient infection as a trigger of cardiovascular disease : the ARIC study. J Am Heart Assoc. 2018 ;7 (22): e009683-e009683. doi :10.1161/JAHA.118. 009683

3. Madjid M, Miller CC, Zarubaev VV, et al. Influenza epidemics and acute respiratory disease activity are associated with a surge in autopsy-confirmed coronary heart disease death : results from 8 years of autopsies in 34,892 subjects. Eur Heart J. 2007 ;28(10): 1205-1210. doi :10.1093/eurheartj/ ehm035.

4. Fauci AS, Lane HC, Redfield RR. Covid-19 : navigating the uncharted. N Engl J Med. 2020. doi: 10.1056/NEJMe2002387

5. Dhainaut J-F, Claessens Y-E, Janes J, Nelson DR. Underlying disorders and their impact on the host response to infection. Clin Infect Dis. 2005 ;41(suppl7) : S481-S489. doi :10.1086/432001

6. Fehr AR, Perlman S. Coronaviruses : an overview of their replication and pathogenesis. Methods Mol Biol. 2015 ;1282:1-23. doi :10.1007/978-1-4939-2438- 7_1

7. Zhang S-F, Tuo J-L, Huang X-B, et al. Epidemiology characteristics of human coronaviruses in patients with respiratory infection symptoms and phylogenetic analysis of HCoV-OC43 during 2010-2015 in Guangzhou. PloS One. 2018 ;13(1) : e0191789-e0191789. doi: 10.1371/journal.pone.0191789

8. Team TNCPERE. The epidemiological characteristics of an outbreak of 2019 novel coronavirus diseases (COVID-19) -China, 2020 (J). China CDCWeekly. 2020 ;2(8):113-122.

9. Chen N, Zhou M, Dong X, et al. Epidemiological and clinical characteristics of 99 cases of 2019 novel coronavirus pneumonia in Wuhan, China : a descriptive study. Lancet. 2020 ;395(10223):507- 513. doi :10.1016/S0140-6736(20)30211-7

10. Su S, Wong G, Shi W, et al. Epidemiology, genetic recombination, and pathogenesis of coronaviruses. Trends Microbiol. 2016 ;24(6):490-502. doi :10.1016/ j.tim.2016.03.003

11. LiW, Hulswit RJG, Kenney SP, et al. Broad receptor engagement of an emerging global coronavirus may potentiate its diverse cross-species transmissibility. Proc Natl Acad Sci U SA. 2018;115(22):E5135-E5143. doi:10.1073/pnas.1802879115.

12. El-Sahly HM, Atmar RL, Glezen WP, Greenberg SB. Spectrum of clinical illness in hospitalized patients with "common cold" virus infections. Clin Infect Dis. 2000 ;31(1):96-100. doi :10.1086/313937.

13. Imai Y, Kuba K, Rao S, et al. Angiotensin converting enzyme 2 protects from severe acute lung failure. Nature. 2005 ;436(7047) :112-116. doi : 10.1038/nature03712. 
14. Bonow RO, Fonarow GC, O'Gara PT, Yancy CW. Association of coronavirus disease 2019 (COVID-19) with myocardial injury and mortality. JAMA Cardiol 2020;5:751-3.

15. Driggin E, Madhavan MV, Bikdeli B, et al. Cardiovascular considerations for patients, health care workers, and health systems during the coronavirus disease 2019 (COVID-19) pandemic. J Am Coll Cardiol 2020;75:2352-71.

16. Bikdeli B, Madhavan MV, Jimenez D, et al., for the Global COVID-19 Thrombosis Collaborative Group. COVID-19 and thrombotic or thromboembolic disease : implications for prevention, antithrombotic therapy, and follow-up : JACC Stateof the- Art Review. J Am Coll Cardiol $2020 ; 75: 2950-73$.

17. Wang A, Mandigo GK, et al. Stroke and mechanical thrombectomy in patients with COVID-19: technical observations and patient characteristics. J Neuro Intervent Surg. 2020 Jul ;12(7) :648-53.

18. Viguier A, Delamarre L, Duplantier J, et al. Acute ischemic stroke complicating common carotid artery thrombosis during a severe COVID-19 infection. Journal of Neuroradiology. 2020 May ; S0150986120301590.

19. Fara MG, Stein LK, Skliut M, et al. Macrothrombosis and stroke in patients with mild Covid-19 infection. J Thromb Haemost. 2020 May 28 ; jth.14938

20. Román GC, Reis J, Spencer PS, Buguet A, Öztürk S, Wasay M ; World Federation of Neurology Environmental Neurology Specialty Group COVID-19 international neurological registries. Lancet Neurol. 2020 Jun;19(6):484-485

21. Tassorelli C, Mojoli F, Baldanti F, Bruno R, Benazzo M. COVID-19: what if the brain had a role in causing the deaths? Eur J Neurol. 2020 Sep ;27(9) : e41-e42.

22. Mao L, Jin H, Wang M, Hu Y, Chen S, He Q, et al. Neurologic Manifestations of Hospitalized Patients With Coronavirus Disease 2019 in Wuhan, China. JAMA Neurol. 2020 Jun 1 ;77(6) :683-690

23. Klok FA, Kruip M, van der Meer NJM, et al. Incidence of thrombotic complications in critically ill ICU patients with COVID-19. Thromb Res $2020 ; 191: 145-7$.

24. Tang N, Li D, Wang X, Sun Z. Abnormal coagulation parameters are associated with poor prognosis in patients with novel coronavirus pneumonia. J Thromb Haemost 2020 ; 18:844-7. Cui S, Chen S, Li X, Liu S, Wang F. Prevalence of venous thromboembolism in patients with severe novel coronavirus pneumonia. J Thromb Haemost $2020 ; 18: 1421-4$.

25. Llitjos JF, Leclerc M, Chochois C, et al. High incidence of venous thromboembolic events in anticoagulated severe COVID19 patients. J Thromb Haemost $2020 ; 18: 1743-6$.

26. Lodigiani C, Iapichino G, Carenzo L, et al., for the Humanitas COVID-19 Task Force. Venous and arterial thromboembolic complications in COVID-19 patients admitted to an academic hospital in Milan, Italy. Thromb Res 2020;191:9-14.

27. Marietta M, Ageno W, Artoni A, et al. COVID-19 and haemostasis: a position paper from Italian Society on Thrombosis and Haemostasis (SISET). Blood Transfus $2020 ; 18: 167-9$.

28. Ackermann M, Verleden SE, Kuehnel M, et al. Pulmonary vascular endothelialitis, thrombosis, and angiogenesis in Covid19. N Engl J Med $2020 ; 383: 120-8$.

29. Wichmann D, Sperhake JP, Lutgehetmann M, et al. Autopsy findings and venous thromboembolism in patients with COVID-19. Ann Intern Med $2020 ; 173$ :268-77.

30. Fosse JH, Haraldsen G, Falk K, Edelmann R. Endothelial cells in emerging viral infections. Front Cardiovasc Med 2021 ; 8 : 619690. 
31. Moores LK, Tritschler T, Brosnahan S, et al. Prevention, diagnosis and treatment of VTE in patients with coronavirus disease 2019 : CHEST guideline and expert panel report. Chest 2020 ; 158 :1143-63.

32. Spyropoulos AC, Levy JH, Ageno W, et al. Scientific and Standardization Committee communication : clinical guidance on the diagnosis, prevention and treatment of venous thromboembolism in hospitalized patients with COVID-19. J Thromb Haemost $2020 ; 18: 1859-65$.

33. Tang N, Bai H, Chen X, Gong J, Li D, Sun Z. Anticoagulant treatment is associated with decreased mortality in severe coronavirus disease 2019 patients with coagulopathy. J Thromb Haemost $2020 ; 18: 1094-9$.

34. Weiss, S.R.; Navas-Martin, S. Coronavirus pathogenesis and the emerging pathogen severe acute respiratory syndrome coronavirus. Microbiol. Mol. Biol. Rev. 2005, 69, 635-664

35. Perlman, S, Netland, J. Coronaviruses post-SARS : Update on replication and pathogenesis. Nat. Rev. Microbiol. 2009, 7, 439-450.

36. Belouzard S, Millet JK, Licitra BN, Whittaker GR. Mechanisms of coronavirus cell entry mediated by the viral spike protein. Viruses. 2012 Jun ;4(6):1011-33.

37. Li Q, Guan X,Wu P, et al. Early transmission dynamics in Wuhan, China, of novel coronavirus-infected pneumonia. N Engl J Med. 2020.doi:10.1056/NEJMoa2001316

38. Lu R, Zhao X, Li J, et al. Genomic characterisation and epidemiology of 2019 novel coronavirus : implications for virus origins and receptor binding. Lancet. 2020 ;395(10224) : 565-574.doi :10.1016/S0140-6736(20)30251-8

39. Liang W, Zhu Z, Guo J, et al ; Beijing Joint SARS Expert Group. Severe acute respiratory syndrome, Beijing, 2003. Emerg Infect Dis. 2004 ;10(1):25-31. doi:10.3201/eid1001.030553

40. Aleanizy FS, Mohmed N, Alqahtani FY, El Hadi Mohamed RA Outbreak of Middle East respiratory syndrome coronavirus in Saudi Arabia : a retrospective study. BMC Infect Dis. 2017 Jan 5;17(1):23.

41. Paules CI, Marston HD, Fauci AS. Coronavirus infections-more than just the common cold. JAMA. Published online January 23, 2020. doi:10.1001/jama.2020.0757

42. Wu JT, Leung $\mathrm{K}$, Leung GM. Nowcasting and forecasting the potential domestic and international spread of the 2019-nCoV outbreak originating inWuhan, China: a modelling study.Lancet. Published online January 31, 2020. doi:10. 1016/S0140-6736(20)30260-9

43. Cohen J. Mining coronavirus genomes for clues to the outbreak's origins. Science. Published online January 31, 2020. doi :10.1126/science. abb1256

44. del Rio C, Malani PN. 2019 Novel coronavirus-important information for clinicians [published February 5, 2020]. JAMA. doi :10.1001/ jama.2020.1490

45. Chan JF-W, Kok K-H, Zhu Z, et al. Genomic characterization of the 2019 novel human-pathogenic coronavirus isolated from a patient with atypical pneumonia after visiting Wuhan. Emerg Microbes Infect. 2020 ;9(1): 221236.doi:10.1080/22221751.2020.1719902

46. Andersen KG, Rambaut A, Lipkin WI, Holmes EC, Garry RF. The proximal origin of SARS-CoV-2. Nat Med. 2020 Apr ;26(4) :450-452. doi: 10.1038/s41591-020-0820-9.

47. Kuba K, Imai Y, Rao S, Jiang C, Penninger JM. Lessons from SARS : control of acute lung failure by the SARS receptor ACE2. J Mol Med (Berl). 2006 Oct ;84(10) :814-20. doi: 10.1007/s00109-006-0094-9. Epub 2006 Sep 19. 
48. Li F. Receptor recognition mechanisms of coronaviruses : a decade of structural studies. J Virol. 2015 Feb;89(4):1954-64. doi: 10.1128/JVI.02615-14. Epub 2014 Nov 26

49. Hoffmann M, Kleine-Weber H, Pöhlmann S. A Multibasic Cleavage Site in the Spike Protein of SARS-CoV-2 Is Essential for Infection of Human Lung Cells. Mol Cell. 2020 May 21;78(4):779-784.e5. doi: 10.1016/j.molcel.2020.04.022. Epub 2020 May 1.

50. Zhou P, Yang XL, Wang XG et al. A pneumonia outbreak associated with a new coronavirus of probable bat origin. Nature $2020 ; 579: 270-273$.

51. Andersen KG, Rambaut A, Lipkin WI, Holmes EC, Garry RF The proximal origin of SARS-CoV-2. Nat Med. 2020 Apr ;26(4) :450-452. doi: 10.1038/s41591-020-0820-9.

52. Laporte M, Raeymaekers V, Van Berwaer R et al. The SARS-CoV-2 and other human coronavirus spike proteins are finetuned towards temperature and proteases of the human airways. PLoS Pathog $2021 ; 17$ : e1009500

53. Daly JL, Simonetti B, Klein K et al. Neuropilin-1 is a host factor for SARS-CoV-2 infection. Science 2020 ; 370 : $861-865$.

54. Teuwen LA, Geldhof V, Pasut A, Carmeliet P. COVID-19 : the vasculature unleashed. Nat Rev Immunol $2020 ; 20: 389-391$.

55. Hoffmann M, Kleine-Weber H, Schroeder S et al. SARS-CoV- 2 cell entry depends on ACE2 and TMPRSS2 and is blocked by a clinically proven protease inhibitor. Cell $2020 ; 181: 271-280 . e 278$

56. Gerhardt H, Ruhrberg C, Abramsson A, Fujisawa H, Shima D, Betsholtz C. Neuropilin-1 is required for endothelial tip cell guidance in the developing central nervous system. Develop Dynam 2004 ; 231 : 503-509.

57. Jones EA, Yuan L, Breant C, Watts RJ, Eichmann A. Separating genetic and hemodynamic defects in neuropilin 1 knockout embryos. Development 2008 ;135 : 2479-2488.

58. Aspalter IM, Gordon E, Dubrac A et al. Alk1 and Alk5 inhibition by Nrp1 controls vascular sprouting down Stream of Notch. Nat Commun $2015 ; 6: 7264$

59. Cantuti-Castelvetri L, Ojha R, Pedro LD et al. Neuropilin- 1 facilitates SARS-CoV-2 cell entry and infectivity. Science 2020; 370: $856-860$.

60. Zhou F, Yu T, Du R, et al. Clinical course and risk factors for mortality of adult in patients with COVID-19 in Wuhan, China : a retrospective cohort study. Lancet $2020 ; 395: 1054-62$.

61. Gu SX, Tyagi T, Jain K et al. Thrombocytopathy and endotheliopathy : crucial contributors to COVID-19 thromboinflammation. Nat Rev Cardiol $2021 ; 18: 194-209$.

62. Goshua G, Pine AB, Meizlish ML et al. Endotheliopathy in COVID-19-associated coagulopathy : evidence from a singlecentre, cross-sectional study. Lancet Haematol

$2020 ; 7$ : e575-e582.

63. Smadja DM, Mentzer SJ, Fontenay M et al. COVID-19 is a systemic vascular hemopathy: insight for mechanistic and clinical aspects. Angiogenesis $2021 ; 24: 755-788$.

64. Sardu C, Gambardella J, Morelli MB, Wang X, Marfella R, Santulli G. Hypertension, thrombosis, kidney failure, and diabetes : is COVID-19 an endothelial disease ? A comprehensive evaluation of clinical and basic evidence. J Clin Med 2020 ; $9: 1417$.

65. Gupta A, Madhavan MV, Sehgal K et al. Extrapulmonary manifestations of COVID-19. Nat Med $2020 ; 26: 1017-1032$.

66. Vickers C, Hales P, Kaushik V, et al. Hydrolysis of biological peptides by human angiotensin-converting enzyme-related carboxypeptidase. J Biol Chem $2002 ; 277: 14838-43$. 
67. Hamming I, Timens W, Bulthuis MLC, Lely AT, Navis GJ, van Goor H. Tissue distribution of ACE2 protein, the functional receptor for SARS coronavirus : a first step in understanding SARS pathogenesis. J Pathol 2004 ; 203 : 631-7.

68. Serfozo P, Wysocki J, Gulua G, et al. Ang II (angiotensin II) conversion to angiotensin-(1-7) in the circulation is POP (prolyloligopeptidase)-dependent and ACE2 (angiotensin-converting enzyme 2) -independent. Hypertension 2020 ; 75 : $173-82$.

69. Rice GI, Thomas DA, Grant PJ, Turner AJ, Hooper NM. Evaluation of angiotensin-converting enzyme (ACE), its homologue ACE2 and neprilysin in angiotensin peptide metabolism. Biochem J $2004 ; 383: 45-51$.

70. Ferrario CM, Jessup J, Chappell MC, et al. Effect of angiotensin- converting enzyme inhibition and angiotensin II receptor blockers on cardiac angiotensin-converting enzyme 2. Circulation

$2005111: 2605-10$.

71. Ocaranza MP, Godoy I, Jalil JE, et al. Enalapril attenuates downregulation of angiotensin-converting enzyme 2 in the late phase of ventricular dysfunction in myocardial infarcted rat. Hypertension $2006 ; 48: 572-8$.

72. Vuille-dit-Bille RN, Camargo SM, Emmenegger L, et al. Human intestine luminal ACE2 and amino acid transporter expression increased by ACE-inhibitors. Amino Acids $2015 ; 47: 693-705$.

73. Sukumaran V, Tsuchimochi H, Tatsumi E, Shirai M, Pearson JT. Azilsartan ameliorates diabetic cardiomyopathy in young $\mathrm{db} / \mathrm{db}$ mice through the modulation of ACE-2/ANG 1-7/Mas receptor cascade. Biochem Pharmacol 2017; 144: 90-9.

74. Sukumaran V, Veeraveedu PT, Lakshmanan AP, et al. Olmesartan medoxomil treatment potently improves cardiac myosininduced dilated cardiomyopathy via the modulation of ACE-2 and ANG 1-7 Mas receptor. Free Radic Res 2012 ; 46 : $850-$ 60.

75. Sukumaran V, Veeraveedu PT, Gurusamy N, et al. Olmesartan attenuates the development of heart failure after experimental autoimmune myocarditis in rats through the modulation of ANG 1-7 Mas receptor. Mol Cell Endocrinol 2012 ; 351 : 208 19.

76. Lakshmanan AP, Thandavarayan RA, Watanabe K, et al. Modulation of AT-1R/MAPK cascade by an olmesartan treatment attenuates diabetic nephropathy in streptozotocin-induced diabetic mice. Mol Cell Endocrinol $2012 ; 348$ : $104-11$.

77. Burchill LJ, Velkoska E, Dean RG, Griggs K, Patel SK, Burrell LM. Combination renin-angiotensin system blockade and angiotensin- converting enzyme 2 in experimental myocardial infarction : implications for future therapeutic directions. Clin Sci (Lond) 2012 ; 123 : 649-58.

78. Campbell DJ, Zeitz CJ, Esler MD, Horowitz JD. Evidence against a major role for angiotensin converting enzyme-related carboxypeptidase (ACE2) in angiotensin peptide metabolism in the human coronary circulation. J Hypertens $2004 ; 22$ : 1971-6.

79. Luque M, Martin P, Martell N, Fernandez C, Brosnihan KB, Ferrario CM. Effects of captopril related to increased levels of prostacyclin and angiotensin-(1-7) in essential hypertension.

J Hypertens $1996 ; 14: 799-805$.

80. Furuhashi M, Moniwa N, Mita T, et al. Urinary angiotensinconverting enzyme 2 in hypertensive patients may be increased by olmesartan, an angiotensin II receptor blocker. Am J Hypertens

$2015 ; 28: 15-21$.

81. Lambert DW, Yarski M, Warner FJ, et al. Tumor necrosis factor- $\alpha$ convertase (ADAM17) mediates regulated ectodomain shedding of the severe-acute respiratory syndrome-coronavirus (SARS-CoV) receptor, angiotensin-converting enzyme-2 (ACE2). J Biol Chem $2005 ; 280$ : 30113-9. 
82. Gurwitz D. Angiotensin receptor blockers as tentative SARS CoV-2 therapeutics. Drug Dev Res 2020 March 4 (Epub ahead of print).

83. Liu Y, Yang Y, Zhang C, et al. Clinical and biochemical indexes from 2019-nCoV infected patients linked to viral loads and lung injury. Sci China Life Sci 2020; 63: 364-74.

84. Sodhi CP, Wohlford-Lenane C, Yamaguchi Y, et al. Attenuation of pulmonary ACE2 activity impairs inactivation of desArg9 bradykinin/BKB1R axis and facilitates LPS-induced neutrophil infiltration. Am J Physiol Lung Cell Mol Physiol 2018 ; 314 : L17-L31.

85. Hemnes AR, Rathinasabapathy A, Austin EA, et al. A potential therapeutic role for angiotensin-converting enzyme 2 in human pulmonary arterial hypertension. Eur Respir J 2018; 51(6).

86. Tan WSD, Liao W, Zhou S, Mei D, Wong W-SF. Targeting the renin-angiotensin system as novel therapeutic strategy for pulmonary diseases. Curr Opin Pharmacol $2018 ; 40: 9-17$.

87. Shi S, Qin M, Shen B, et al. Association of cardiac injury with mortality in hospitalized patients with COVID-19 in Wuhan, China. JAMA Cardiol 2020 Jul 1;5(7):802-810.

88. Oudit GY, Kassiri Z, Jiang C, et al. SARS-coronavirus modulation of myocardial ACE2 expression and inflammation in patients with SARS. Eur J Clin Invest $2009 ; 39: 618-25$.

89. Basu R, Poglitsch M, Yogasundaram H, Thomas J, Rowe BH, Oudit GY. Roles of angiotensin peptides and recombinant human ACE2 in heart failure. J Am Coll Cardiol 2017 ; 69 : 805-19.

90. Nicin L, Abplanalp WT, Mellentin H et al. Cell typespecific expression of the putative SARS-CoV-2 receptor ACE2 in human hearts. Eur Heart J $2020 ; 41$ : 1804-1806. 16.

91. Sluimer JC, Gasc JM, Hamming I et al. Angiotensinconverting enzyme 2 (ACE2) expression and activity in human carotid atherosclerotic lesions. J Pathol $2008 ; 215: 273-279$.

92. Hikmet F, Mear L, Edvinsson A, Micke P, Uhlen M, Lindskog C. The protein expression profile of ACE2 in human tissues. Mol Syst Biol $2020 ; 16$ : e9610.

93. Monteil V KH, Prado P, Hagelkrüys A, et al. Inhibition of SARS-CoV-2 infections in engineered human tissues using clinicalgrade soluble human ACE2. Cell 2020 ; published online in press. https://www.cell.com/pbassets/ products/coronavirus/CELL_CELL-D-20-00739.pdf (accessed

April 17, 2020).

94. Chen L, Li X, Chen M, Feng Y, Xiong C. The ACE2 expression in human heart indicates new potential mechanism of heart injury among patients infected with SARS-CoV-2. Cardiovasc Res $2020 ; 116: 1097-1100$.

95. McCracken IR, Saginc G, He L et al. Lack of evidence of angiotensin-converting enzyme 2 expression and replicative infection by SARS-CoV-2 in human endothelial cells. Circulation $2021 ; 143: 865-868$

96. Litviňuková M, Talavera-López C, Maatz H, Reichart D, Worth CL, Lindberg EL, Kanda M, Polanski K, Heinig M, Lee M, et al. Cells of the adult human heart. Nature. 2020 ; 588 :466-472. doi : 10.1038/s41586-020-2797-4

97. He L, Mäe MA, Muhl L, Sun Y, Pietilä R, Nahar K, Liébanas EV, Fagerlund MJ, Oldner A, Liu J, et al. Pericyte-specific vascular expression of SARS-CoV-2 receptor ACE2 : implications for microvascular inflammation and hypercoagulopathy in COVID-19. BioRxiv. 2020. https://search.bvsalud.org/global-literature-on-novel-coronavirus-2019ncov/resource/en/ppbiorxiv-088500

98. Rauch A, Dupont A, Goutay J, Caplan M, Staessens S, Moussa M, Jeanpierre E, Corseaux D, Lefevre G, Lassalle F, et al.; Lille COVID Research Network (LICORNE); Members of the LICORNE Scientific Committee. Endotheliopathy is induced 
by plasma from critically Ill patients and associated with organ failure in severe COVID-19. Circulation. 2020 ; 142 :1881188

99. Aimes RT, Zijlstra A, Hooper JD et al. Endothelial cell serine proteases expressed during vascular morphogenesis and angiogenesis. Thromb Haemost $2003 ; 89: 561-572$.

100. Bryce C, Grimes Z, Pujadas E et al. Pathophysiology of SARS-CoV-2 : the Mount Sinai COVID-19 autopsy experience. Mod Pathol $2021 ; 34: 1-12$.

101. Schaefer IM, Padera RF, Solomon IH et al. In situ detection of SARS-CoV-2 in lungs and airways of patients with COVID19. Mod Pathol $2020 ; 33: 2104-2114$.

102. Varga Z, Flammer AJ, Steiger P, Haberecker M, Andermatt R, Zinkernagel AS, Mehra MR, Schuepbach RA, Ruschitzka F, Moch H. Endothelial cell infection and endotheliitis in COVID-19. Lancet. 2020 May 2 ;395(10234):1417-1418

103. Delorey TM, Ziegler CGK, Heimberg G, Normand R, Yang Y, Segerstolpe Å, et al. COVID-19 tissue atlases reveal SARSCoV-2 pathology and cellular targets. Nature. 2021 Jul ;595(7865) :107-113.

104. Lindner D, Fitzek A, Bräuninger H, Aleshcheva G, Edler C, Meissner K, Scherschel K, et al Association of Cardiac Infection With SARS-CoV-2 in Confirmed COVID-19 Autopsy Cases. JAMA Cardiol. 2020 Nov $1 ; 5(11): 1281-1285$

105. Schimmel L, Chew KY, Stocks CJ, Yordanov TE, Essebier P, Kulasinghe A, Monkman J, Dos Santos Miggiolaro AFR, Cooper C, de Noronha L, Schroder K, Lagendijk AK, Labzin LI, Short KR, Gordon EJ. Endothelial cells are not productively infected by SARS-CoV-2. Clin Transl Immunology. 2021 Oct 24 ;10(10): e1350.

106. Magro C, Mulvey JJ, Berlin D, et al. Complement associated microvascular injury and thrombosis in the pathogenesis of severe COVID-19 infection : a report of five cases. Transl Res 2020 April 15 (Epub ahead of print)

107. O’Donnell JS, Sharif K, Emery P, Bridgewood C. McGonagle D. Why the immune mechanisms of pulmonary intravascular coagulopathy in COVID-19 pneumonia are distinct from macrophage activation syndrome with disseminated intravascular coagulation. April 2020

108. Mentzer SJ, Konerding MA. Intussusceptive angiogenesis : expansion and remodeling of microvascular networks. Angiogenesis $2014 ; 17: 499-509$.

109. Zhang Y, Xiao M, Zhang S, et al. Coagulopathy and Antiphospholipid Antibodies in Patients with Covid-19. N Engl J Med. $202023 ; 382(17)$ : e38.

110. Madjid M, Safavi-Naeini P, Solomon SD, et al. Potential Effects of Coronaviruses on the Cardiovascular System : A Review. JAMA Cardiol. 2020 Mar 27 ; 10.1001/jamacardio.2020.1286

111. Yan R, Zhang Y, Li Y, Xia L, Guo Y, Zhou Q. Structural basis for the recognition of SARS-CoV-2 by full-length human ACE2. Science 2020 ; 367 : 1444-8. 